\title{
THE NUCLEAR PATTERN AND FIBER CONNECTIONS OF CERTAIN BASAL TELENCEPHALIC CENTERS IN THE MACAQUE
}

\author{
EDWARD W. LAUER \\ Deparment of Anatomy, University of Michigan, Ann Arbor ${ }^{1}$ \\ EIGHT PLATES (SEVENTEEN FIGURES)
}

INTRODUCTION

This paper dealing with the mammalian forebrain is one of a series of studies which are being carried on in the Laboratory of Comparative Neurology at the University of Michigan. Macaca mulatta was selected in order to provide an anatomical basis for certain experimental work on the non-cortical basal areas of primates. Although some work has been done on these areas in primates, none has given the detailed information concerning nuclear structure and fiber connections required for the type of experimental work planned.

For this study four series of transversely-cut sections were available from the Huber Neurological Collection of the University of Michigan. Two of these series were prepared by the Weil method; the others by a modified toluidin blue method (Huber, '27). One of the Weil and one of the toluidin blue series were cut 20 microns thick; the other two were 30 microns. Photomierographs have been used for illustrations.

For the generous grant which made possible this research, the writer wishes to thank the Horace H. Rackham School of Graduate Studies of the University of Michigan. Especially does he wish to express his gratitude to Prof. Elizabeth C. Crosby for her inspiration and unfailing cooperation in the preparation of this paper.

\section{DESCRIPTION OF NUOLEAR GROUPS}

\section{Olfactory formation and the anterior olfactory nucleus}

As an excellent description of these nuclear masses in the macaque has been given by Crosby and Humphrey ('39), there is no need to

\footnotetext{
${ }^{1}$ A dissertation submitted in partial fulfillment of the requirements for the degree of doctor of philosophy.
} 
do more here than to mention some characteristic features in the macaque. Structurally, the bulb presents the same concentric lamination characteristic of most mammals (figs. 1,4 ) but is less well developed than in many subprimates. These layers tend to assume a crescent shape on each of the four sides of the bulb, being concave toward the incoming olfactory fila, and thus divide the olfactory formation into dorsal, medial, ventral and lateral sectors. Crosby and Humphrey ('39) reported an accessory olfactory bulb only on the left side in one of the toluidin blue series studied and stated that it was apparently absent in the other series considered. Their observations have been confirmed by the present writer, who has in addition, however, found a small accessory olfactory formation in one of the newly prepared Weil series (fig. 4). This, also, was present only on the left side. The anterior olfactory nueleus (figs. 2, 3, 6, 7, 11, 12) of the macaque is small. Its gray can be divided into the typical sub-divisions reported for most mammals, except that no pars externa was observed. As the crus passes into the hemisphere the largest division, pars dorsalis, merges with the overlying cortex (fig. 11). Pars medialis becomes contiguous with the anterior continuation of the hippocampus (fig. 3). The deep staining cells of pars lateralis can be traced laterally until they join the pyriform lobe (figs. 6, 7). The poorly developed pars ventralis (figs. 11, 12) is continuous with the polymorph layer of tuberculum olfactorium which lies behind it. Although Crosby and Humphrey ('39) report no pars posterior in their material, a cell mass corresponding to this division in other mammals was observed in one of the Weil series (fig. 3). It lies slightly lateral to pars medialis, and extends caudally for some distance, to finally grade over into the rostromedial part of tuberculum olfactorium.

\section{Tuberculum olfactorium}

Tuberculum olfactorium (figs. 6, 13) lies close to the brain surface behind the anterior olfactory nucleus, the pars ventralis of which is continuous with its polymorph layer. Its caudal boundary is the nucleus of the diagonal band of Broca. The pyriform cortex marks its lateral extent. On the medial side it is in relationship rostrally with the cortex of the caudal tip of gyrus subcallosus and then with the anterior continuation of the hippocampus, and caudally with the medial septal nucleus and the nucleus of the diagonal band of Broca. Dorsally its exact boundary is difficult to determine, as in many places no clear separation exists between it and the caudate nucleus and the nucleus accumbens lying above it rostrally, and the putamen and the globus pallidus sit- 
uated more caudally. In some places its boundary is partially marked by small islands of Calleja. Tuberculum olfactorium is narrow at its cephalic end, then widens out caudally until the nucleus of the diagonal band of Broca begins to swing caudolaterally and to encroach upon its medial side.

In most planes plexiform, pyramidal and polymorph layers are distinguishable (fig. 6) as in many other mammals (Beccari, '10; M. Young, '36; Fox, '40; Crosby and Humphrey, '41). Rostrally these are only demonstrable on the lateral side; the more medial portion of the tuberculum consists of a single cell layer crowded between the caudate nucleus and the plexiform layer. The pyramidal layer is composed predominantly of small granule cells among which are small and medium-sized pyramidal cells. In some places, particularly on the medial side, clusters of these cells project into the polymorph layer, giving a scalloped appearance to the latter. Toward the pyriform lobe, there is some folding in the cortical layer such as was described in man by Crosby and Humphrey ('41). These folds, however, are not so large as in man, nor are they constant at all levels. The polymorph layer contains some pyramidal cells as well as some of the characteristic large neurons to which Obenchain ('25) has called particular attention.

Small granular islands of Calleja occur in the polymorph layer, particularly along its dorsal and medial edges. The largest island (the medial island of Calleja) lies medial to the anterior end of tuberculum olfactorium (figs. 6,13). It projects upward between nucleus accumbens and the precommissural septum. This island consists of small granule cells, among which are pockets of large neurons (fig. 6). From this medial island, fingers of granule cells extend downward toward the ventral surface to become continuous laterally with the cortical layer of tuberculum olfactorium.

\section{Septal area}

The term septal area (see Ariëns Kappers, Huber and Crosby, '36) is used here to designate that portion of the medial hemisphere wall which lies below corpus callosum, between the frontal cortex rostrally and the anterior commissure caudally. A varied terminology has been used in describing this region; Elliot Smith employed the term corpus precommissurale $(1896,1897$ ) and corpus paraterminale ('03), and Johnston ('13) named it the parolfactory area.

Lateral septal nucleus (figs. 6,12-14). In planes through the caudal portion of the olfactory crus, the lateral septal nucleus appears along 
the lateral wall of septum pellucidum between the body and the rostrum of corpus callosum (fig. 12). More caudally, with the decrease of cortex in the medial wall, the nucleus spreads ventrally along the lateral ventricle and, near its ventral tip, comes into close relationship with nucleus accumbens (figs. 6, 13).

The anterior and dorsal part of the lateral septal nucleus contains medium-sized triangular and spindle-shaped neurons, but the ventral part is formed from a denser mass of slightly smaller cells. As the anterior commissure is approached, the dorsal portion fades out and the ventral portion of the nucleus is continued caudally over the foramen of Monro. This caudal extension is composed of a dense mass of small, pale, round cells, which for a short distance extend to the midline, the two nuclei forming a continuous mass beneath the fornix. This supraforaminal part of the lateral septal nucleus apparently corresponds to nucleus septalis fimbrialis of Loo ('31) and others. This name would not be appropriate, however, in the macaque, as the much greater development of corpus callosum has extended the septum so far caudally that this portion of the lateral septal nucleus is now contiguous with the fornix and not with the fimbria. A. Young ('26) considered nucleus septalis fimbrialis as a caudal continuation of both the medial septal and the lateral septal nuclei. Loo ('31), M. Young ('36) and Fox ('40) reported it only as an extension of the latter nucleus. In the macaque, though the main mass of cells is continuous with the lateral septal nucleus, a few neurons located near the midline below the fornix might be considered as a caudal extension of the medial septal nucleus.

In planes slightly caudal to the middle of the lateral septal nucleus, a small, oval-shaped, discreet group of dark-staining cells is visible on the medial edge of the ventral part of this nucleus. Whether these are interstitial cells in some fiber tract, or are of any particular significance is not demonstrable at this time. No mention of such a cell mass has been made in any of the other literature on this area.

Medial septal nucleus (figs. 6,13 ) The rostral end of the medial septal nucleus lies considerably caudal to the cephalic tip of the lateral septal nucleus. Its scattered cells are between the lateral septal nucleus and the free edge of the septal area along the dorsal tip of the ventral fissure. It spreads ventro-caudally, posterior to the anterior continuation of the hippocampus. Ventrolaterally no sharp distinction exists between the medial septal nucleus and the nucleus of the diagonal band of Broca, the neurons of this band being possibly slightly larger and deeper staining. The bed nuclens of the anterior commissure divides the medial septal nucleus into a small dorsal portion, which soon 
disappears, and a larger ventral portion which is continuous with the nucleus of the diagonal band of Broca. The cells of the medial septal nucleus are predominantly medium-sized and fusiform in the anterior and dorsal parts. In the ventral and caudal regions they are somewhat larger resembling those of the nucleus of the diagonal band of Broca.

Nucleus of the diagonal band of Broca (figs. 6, 13, 14). This band of large multipolar neurons stretches from the medial part of the septal area to the basal centers of the lateral hemisphere wall, bounding the caudal extremity of tuberculum olfactorium. Rostrally it is in close relationship with the medial septal nucleus above and the medial island of Calleja and the nucleus accumbens laterally. Laterally, it tends to split into a dorsal and a ventral stream of cells. The dorsal part mingles with the cells of globus pallidus and the ventral portion invades the anterior amygdaloid area to come into intimate relationship with the medial and the central amygdaloid nuclei.

Nucleus accumbens (fig. 13). Although this is apparently a continuation of the striatal complex, it is included here because it extends around the ventricle into the septal area and because its connections resemble those of the septal region. Its cells are like those of the caudate nucleus. Anteriorly, on its ventromedial border, it approaches the caudal end of the anterior olfactory nucleus. It is replaced, on its medial border, by the medial island of Calleja. Dorsomedially it is contiguous with the lateral septal nucleus; posteriorly it is confluent with the bed nuclei of the anterior commissure and the stria terminalis.

Bed nuclei of the anterior commissure and the stria terminalis (figs. (figs. 6, 14). As the anterior commissure approaches the midline, a large gray mass appears rostral and ventral to it, the bed nucleus of the anterior commissure. It is first seen as the limbs of the commissure assume a position below the tip of the ventricle, and it soon spreads medially and ventrally to form a single continuous mass across the midline. It extends caudally under the commissure for a short distance. Dorsolaterally its neurons are not distinguishable from those of the bed nucleus of stria terminalis.

Below the caudate nucleus, interspersed among the fibers of the stria terminalis along the lower lateral wall of the ventricle, are neurons which form its bed nucleus. Anteriorly this bed nucleus is confluent with that of the anterior commissure. Posteriorly it accompanies the stria as far as the anterior thalamic nuclei (Gurdjian, '27, and others).

Nucleus septalis triangularis (fig. 14). Dorsal to the more rostral part of the anterior commissure, a small, dense cell mass projects up- 
ward between the two descending fornix columns, the nucleus septalis triangularis of Ramón y Cajal ('11) and others and the median preoptic nucleus of Mettler ('42). In the macaque this nucleus extends downward in front of the commissure and slightly caudally along its ventral surface.

Vestigial remnants of the hippocampus (figs. 3, 6, 11, 12). Pars medialis of the anterior olfactory nucleus merges medially, near the base of the olfactory peduncle, with the ventral end of the anterior continuation of the hippocampus. It can be traced posteriorly under the frontal cortex until it turns dorsorostrally to pass upward through the septal region to a position just below the corpus callosum. In one of the series studied these cells cannot be traced through the middle of the septal area, but in the other they are demonstrable for the entire distance. Under corpus callosum, the anterior continuation of the hippocampus splits into two parts, one of which can be traced rostrally around the genu of corpus callosum and onto its dorsal surface. Here it passes caudalward near the midline to become continuous with the main mass of the hippocampus. This is the indusium griseum (fig. 6). Also passing caudally from the anterior continuation of the hippocampus, but ventral to corpus callosum, is a second gray mass consisting of intermittent groups of cells, each group containing from two or three to a dozen neurons. These cell clusters represent what is left in the macaque of nucleus septalis hippocampalis of lower forms (M. Young, '36; Humphrey, '36).

\section{The amygdaloid complex}

The amygdala of Macaca mulatta contains all the nuclear groups customarily described in mammals. It is quite similar to that of man (Crosby and Humphrey, '41). For purposes of description the complex may be divided into four groups (Humphrey, '36; Crosby and Humphrey, '41) : (1) the anterior amygdaloid area, (2) the baso-latera] group, (3) the cortico-medial group, and (4) the cortico-amygdaloid transition area. Fox ('40) placed the nucleus of the lateral olfactory tract with the anterior amygdaloid area in an anterior group.

Anterior amygdaloid area. In a plane slightly caudal to the rostral edge of the anterior commissure, undifferentiated gray, the anterior amygdaloid area, appears between the claustrum laterally and the cortex medially. This increases until. it occupies all the area between the pyriform cortex and the substriatal gray. Caudally it is encroached upon by the various amygdaloid nuclei (figs. 7 to 9) until it is reduced to a small region between the central and the medial 
amygdaloid nuclei, dorsal to the accessory basal amygdaloid nucleus. In the caudal third of the amygdaloid complex, this region is crossed by numerous fiber strands (figs. 10,15,16) among which are interspersed the more caudal neurons of the anterior amygdaloid area. In general this area is composed of small polymorph cells. However, in the cephalic end there are a considerable number of medium-sized cells intermingled with the smaller neurons, particularly in the dorsal region.

Baso-lateral group. The baso-lateral nuclear mass is relatively much larger than the cortico-medial group, occupying in general about three-fourths of the amygdaloid complex. The baso-lateral group (fig. 7) extends from a plane near the rostral border of the anterior commissure to the caudal tip of the amygdaloid complex. It is clearly divisible into lateral, basal and accessory basal amygdaloid nuclei, which correspond with those described by Johnston ('23) for the monkey. The intercalated masses may be included in this group. Throughout most of the complex, these nuclei are almost completely separated from each other by fiber fascicles. At the rostral and caudal tips there is an intermingling of the cells of the lateral and basal nuclei, and at practically all levels there is no distinct separation between the ventral part of the lateral amygdaloid nucleus and the ventral part of the basal (figs. 9, 10, 15). The baso-lateral group is bounded by the external capsule and ventrally by the temporal component of the anterior commissure, except caudally where these nuclei lie along the lateral ventricle.

Lateral amygdaloid nucleus ( $f$ igs.7-10,15, 16). The lateral amygdaloid nucleus is the first of the differentiated amygdaloid cell masses to appear rostrally, its cells being found among those of a large intercalate mass lying in the ventral half of the anterior amygdaloid area (fig. 7). It rapidly increases to form a large oval mass extending dorsally from the ventral surface of the complex to the anterior commissure. For its extent it lies between the basal amygdaloid nucleus medially and the external capsule laterally except where its caudal pole borders the lateral ventricle. With the extension laterally of the anterior commissure, the lateral amygdaloid nucleus is related to the putamen dorsally, except where the dorsal tip of the basal amygdaloid nucleus is interposed (fig. 9). Still farther caudally it is contiguous with the tail of the caudate nucleus, maintaining this relationship until the hippocampus and the cephalic end of the ventricle intervene. The lateral nucleus gradually decreases in size, beginning dorsally. With the appearance of the hippocampus, there is a merging of the cells of the lateral and basal amygdaloid nuclei, and this common area soon com- 
pletely disappears. There was a discrepancy in the position of this common area on the two sides of one of the brains studied. On one side it was displaced medially by the hippocampus, on the other side it lay ventral to the hippocampus with its caudal end below the cephalic end of the ventricle. In its rostral half, in particular, the dorsal part of the lateral nucleus is frequently broken into by fiber bundles passing forward to the anterior commissure (figs. 9, 15). In many planes it also was separated from the putamen-caudate complex by small fascicles among which were frequently interspersed tiny masses of intercalate cells (fig. 10). At all levels fiber bundles separate it from the lateral part of the basal amygdaloid nucleus. This separation is somewhat indistinct between the ventral parts of the two nuclei, so that there are intermingled cells in this region. The lateral nucleus consists of a fairly dense mass of small and medium-sized cells, none of which, however, approach in size those of the lateral part of the basal amygdaloid nucleus.

Basal amygdaloid nucleus ( figs. $7-10,15,16$ ). The cephalic end of the basal amygdaloid nucleus appears just caudal to the rostral tip of the lateral nucleus and indistinctly separated from it. Soon, however, it forms a separate, easily distinguishable mass medial to the lateral nucleus. The basal nucleus can be divided into a lateral, large-celled part and a medial, small-celled part. At first the lateral part has two distinet subdivisions (fig. 8). The ventral subdivision is continuous with the small-celled portion of the basal nucleus and the dorsal subdivision forms an independent, irregular mass of cells dorsomedial to the lateral nucleus. Farther caudalward these two sections join and then the dorsal tip of the nucleus forms a cap over the lateral amygdaloid nucleus, completely separating it from the putamen (fig. 9). Still more caudally the dorsal tip of the basal nucleus projects into close proximity to the central amygdaloid nucleus, from which it is separated by small downward streaming fiber bands (fig. 10). Toward the caudal end of the amygdaloid complex, the lateral part of the basal nucleus dwindles in size and finally merges with the lateral nucleus. The cells of the lateral part are large, multipolar neurons, probably the largest cells in the complex.

The medial or small-celled portion of the basal amygdaloid nucleus can be divided further into a deep and a superficial portion (figs. 8-10). The superficial part consists of a gray band which merges laterally with the lateral amygdaloid nucleus and medially, in many planes, with the pyriform cortex or with the cortico-amygdaloid transition area which at these levels lies between the pyriform cortex and the amygdaloid 
complex. The deeper part of pars medialis passes over gradually into pars lateralis of the basal nucleus. It is composed of small cells ventrally which become interspersed more and more with larger cells as the lateral part of the nucleus is approached. Its medial tip is contiguous with the medial part of the accessory basal nucleus, being at many levels, particularly in the caudal half, not sharply delimited from it. It also tends to merge with the lateral nucleus, especially in the caudal part (fig. 10).

Accessory basal amygdaloid nucleus (figs. 8-10, 15, 16). The accessory basal nucleus can be divided into a lateral, large-celled portion and a medial, smaller-celled part. The medial part appears somewhat caudal to the rostral pole of the basal amygdaloid nucleus and is followed soon by the large-celled portion (figs. 8-10). Caudally both increase until their oval-shaped mass is the largest of the nuclear groups. They are the last of the nuclear groups to disappear. The lateral part, composed of cells nearly as large as those of the lateral portion of the basal nucleus, is delimited laterally, dorsally, and medially by quite definite fiber bands. Only near the caudal end does it come in close relationship on its medial side with the cortical amygdaloid nucleus, from which it may be clearly distinguished by the larger size of its cells. On the ventral side it merges with the medial or small-celled portion (figs. $9,10)$. The limits of the medial portion of the accessory basal nucleus are not clearly defined. Medially and ventromedially it tends to merge with the cortical amygdaloid nucleus and the cortico-amygdaloid tran. sition area; on the ventro-caudal border, it is closely associated with the deep portion of pars medialis of the basal nucleus (fig. 10).

Intercalated cell masses (figs. 7-10). Interspersed among the constituent nuclei of the baso-lateral amygdaloid complex are condensed plates of small nerve cells. Völsch' ('10) considered these as glial elements, but Johnston ('23) interpreted them as being true nerve cells, and such is the concensus today. These masses have been described for various subprimates by Berkelbach van der Sprenkel ('26), Humphrey ('36) and Fox ('40) and for man by Crosby and Humphrey ('41). In the macaque these occur especially along the ventral surface and above the dorsal tips of the constituent nuclei. The largest mass is found around the rostral pole of the lateral and basal nuclei, from which position it extends caudally between their dorsal tips for approximately a fourth of the total extent of the complex (figs. 7, 8).

Cortico-medial group. The cortical amygdaloid nucleus, the medial amygdaloid nucleus, the central amygdaloid nucleus, and the nucleus of the lateral olfactory tract constitute the cortico-medial 
amygdaloid complex. With the exception of the cortical amygdaloid nucleus, the nuclei of this group are comparatively small and are not clearly delimited from surrounding areas.

Nucleus of the lateral olfactory tract (figs. 8, 9). This nucleus is the smallest of the amygdaloid nuclei, although apparently larger in macaque than in man (Crosby and Humphrey, '41). Nevertheless it is the most easily circumscribed, due to its characteristically large, deep-staining cells. It is clearly divisible into a caudal and a rostral part, in that respect corresponding to this nucleus in the bat (Humphrey, '36). In planes through the rostral pole of the lateral and basal amygdaloid nuclei, the cortex just medial to them disappears and in this cell-free, superficial area appear the first cells of the rostral section of the nucleus of the lateral olfactory tract. They spread dorsally, forming a narrow band of large, dark-staining cells, which stretches from a point above the center of the cortical amygdaloid nucleus to the ventral edge of the medial amygdaloid nucleus (fig. 8). This rostral nucleus of the lateral olfactory tract then diminishes in size, beginning dorsally. Its more ventral cells are large, multipolar neurons, but its dorsal cells are somewhat smaller. In its rostrocaudal extent there is a variation in one of the brains studied. It extends for a distance of $1.2 \mathrm{~mm}$. on one side but only $0.5 \mathrm{~mm}$. on the other. In a plane showing the most caudal cells of the rostral part of this nucleus, the more rostral cells of the caudal section appear between the medial and the cortical amygdaloid nuclei. This is the position ascribed to this nucleus in man by Crosby and Humpbrey ('41). It extends rostro-caudally about $1.1 \mathrm{~mm}$., but at no place contains over 25 or 30 cells, with only 5 or 6 appearing in many sections. It forms, however, a distinct, circular mass, projecting above the surfaces of the medial and the cortical amygdaloid nuclei (fig. 9).

Cortical amygdaloid nucleus (figs. $9,10,15,16$ ). The cortical amygdaloid nucleus has approximately the same extent as the accessory basal nucleus, but is more superficial. It consists primarily of a dense superficial layer of cells overlying a somewhat thinned-out gray area of variable width. Its rostral limit is in planes through the rostral edge of the circular amygdaloid fissure. Caudally it grades over into the adjacent cortex. It is bounded dorsally by the medial amygdaloid nucleus except where the caudal portion of the nucleus of the lateral olfactory tract intervenes. Laterally there is no clear-cut separation between the cortical and the accessory basal amygdaloid nuclei. Ventrally, at both rostral and caudal poles, the superficial layer of the cortical nucleus merges with the pyriform cortex. Through its central portion it is con- 
tinuous in most planes with the cortico-amygdaloid transition area which lies between it and the pyriform cortex.

The superficial layer, which consists primarily of small to mediumsized pyramidal cells, is not continuous over the entire surface of the nucleus, being broken in the center by an area of loosely arranged cells. The more ventral of the two sections thus formed is thicker than the dorsal, and is underlain by an area with comparatively few neurons. The dorsal section, on the contrary, has beneath it a denser mass of cells which grades over on its deeper surface into the accessory basal amygdaloid nucleus (fig. 10). Although the ventral section extends farther rostrally, the dorsal portion is the last part of the cortical amygdaloid nucleus to be displaced posteriorly.

Medial amygdaloid nucleus (figs. 9, 10, 15, 16). The anterior line of separation between the medial amygdaloid nucleus and the anterior amygdaloid area is indefinite, since the rostral end of the nucleus consists merely of a gradual increase in the cellular density of the medial surface of the anterior amygdaloid area. Caudally, however, the medial nucleus is bordered laterally by fiber bands which separate it from the anterior amygdaloid area and the central nucleus. The medial nucleus is an irregular polyhedral mass of cells wedged between the anterior amygdaloid area and the accessory basal nucleus laterally and the lateral edge of the preoptic region and the optic tract medially. Rostrally it is comparatively wide, but narrows to a thin band posteriorly where it lies along the optic tract. It extends ventrally to the cortical amygdaloid nucleus except for a short space at its rostral end where the nucleus of the lateral olfactory tract intervenes. The medial nucleus consists of small to medium-sized cells but rostrally has a central core of denser, deeper staining neurons.

Central amygdaloid nucleus (figs. 10, 16). The central amygdaloid nucleus appears just caudal to the middle of the amygdaloid complex and extends for about three-fourths of the remaining distance to the caudal pole. This nucleus grades over rostrally into the putamen and the anterior amygdaloid area, and caudally into the substriatal gray. The central amygdaloid nucleus is also very similar cytologically to the putamen, its cells being larger than those of the medial amygdaloid nucleus but smaller than those of the lateral part of the basal nucleus. For most of its extent the central nucleus lies in a pocket between the basal amygdaloid nucleus ventrally, the anterior amygdaloid area and the medial amygdaloid nucleus medially, and the striatal and the substriatal gray laterally and dorsally, from all of which it is separated through much of its extent by fiber fascicles (fig. 10). 
Cortico-amygdaloid transition area (figs. 9, 10). Occupying a position between the pyriform cortex on one side and the basal and the cortical amygdaloid nuclei on the other, particularly through the central half of the amygdaloid complex, is an area which is comparable to the human cortico-amygdaloid transition area (Crosby and Humphrey, '41). In many planes through this area strands of cells run from the cortex to the superficial part of the basal nucleus. On the lateral side the superficial part of the basal amygdaloid nucleus has a direct continuation with the lateral amygdaloid nucleus, thus establishing cellular continuity between the basal and the lateral nuclei and the pyriform cortex. The cortical amygdaloid nucleus and the pyriform cortex are likewise continuous. This continuity between the surface cortex and the amygdaloid gray occurs in other forms (Johnston, '23; Humphrey, '36; Crosby and Humphrey, '41) and would seem to indicate a common genetic origin.

DESCRIPTION OF FIBER TRACTS

\section{Olfactory tracts}

Numerous textbooks and practically all research accounts dealing with the fiber connections of the olfactory regions have described and figured the chief olfactory tracts. This has been done both for submammals and for mammals, including man. In some submammalian forms (e.g., in amphibians, Herrick, '33) the finer connections of these bundles have been described in considerable detail but there has been no comparable analysis of the olfactory tracts in mammals and particularly no detailed account of their relations to the various portions of the anterior olfactory nucleus.

Lateral olfactory tract. The lateral olfactory tract (figs. 4, 5, 11-14) in the macaque is composed primarily of deeply staining fibers from mitral cells of the dorsal, the lateral and the ventrolateral parts of the olfactory formation. Their sources and the positions they occupy in the olfactory crus afford a basis for subdividing the lateral tract into dorsolateral, lateroventral and medioventral parts.

- The dorsolateral portion (figs. 4, 5, 11, 12) is composed of fibers from the dorsal olfactory formation, although there are some from the dorsolateral angle of the bulb. As this is the area where the olfactory formation first disappears, this portion of the tract occupies a superficial position almost from its origin. As the crus flattens out caudally, these fibers form a thin band along the lateral half of the dorsal surface. This band gradually moves laterally and, as the 
cerebral hemisphere is approached, swings ventrolaterally to the most lateral part of the lateral olfactory tract. From this position it sends fibers to pars dorsalis and pars lateralis of the anterior olfactory nucleus.

In planes through the accessory olfactory bulb (fig. 4) fibers pass from it to a position slightly within the medial border of the dorsolateral division. Due to the smallness of the accessory olfactory bulb in the macaque, these fibers are few in number, but they form a small, loose cluster of lighter-staining fascicles which can be followed caudally until the dorsolateral bundle swings ventrally, after which they can no longer be distinguished from the other fibers. This dorsolateral part thus corresponds to the dorsal peduncle in the rabbit as described by M. Young ('36). Later Young ('39), after study of normal and experimental preparations of the rabbit's accessory olfactory bulb, reported that fibers from this bulb ran caudalward in the dorsal and the ventral parts of the lateral olfactory tract.

The lateroventral portion of the lateral olfactory tract (figs. 4, 5, $11,12)$ comes primarily from the mitral cells of the dorsolateral side of the olfactory bulb. These fibers pass dorsally and caudally to occupy the more lateral part of the ventral surface of the crus. The deeper fibers have a lighter staining quality and terminate in the rostral end of pars lateralis of the anterior olfactory nucleus, the first cells of which occur in the area occupied by these bundles. The more superficial fibers also appear to be intimately related to pars lateralis, which at this point lies immediately above them. More caudally, pars lateralis moves laterally and its previous position is occupied by pars ventralis. Thoughout the extent of this portion of the nucleus, there is a continual interchange of fibers between it and the lateroventral portion of the lateral olfactory tract.

The medioventral division (figs. 4, 5, 11, 12) arises from the ventral half of the lateral olfactory formation. The fibers pass dorsally, caudally and slightly medially to occupy a superficial position along the central part of the ventral surface of the crus. This is the largest of the three divisions and makes up at least half of the lateral olfactory tract. It is readily distinguished from the adjacent lateroventral part, by its greater thickness and by the presence of the intermediate olfactory tract directly above it. In some planes, particularly after the attachment of the crus to the hemisphere, there is a small clear area between the medioventral division and the lateroventral division of the lateral olfactory tract, and it is only after they have moved considerably laterally along the surface of the hemisphere that they merge 
and can no longer be distinguished from each other. After the crus joins the cerebral hemisphere (fig. 11), the lateral olfactory tract distributes fibers to various areas. Fibers from the dorsolateral part (fig. 12) pass upward and medialward, between pars lateralis and pars ventralis, to end in the dorsal, the ventral and the lateral parts of the anterior olfactory nucleus, and in part to join the dorsal olfacto-frontal tract for distribution to the overlying cortex. More caudally some fibers, in company with those from pars lateralis of the anterior olfactory nucleus and from the more laterally lying cortex, swing medially above the obliterated lateral ventricle to turn caudally, near the frontal cortex, and enter the medial forebrain bundle. Occasionally small fascicles penetrate the head of the caudale nucleus and the rostral end of nucleus accumbens.

On its medial side the lateroventral division of the lateral olfactory tract exchanges fibers with the intermediate olfactory tract which lies dorsomedially to it. This lateroventral part, however, appears to be connected chiefly with pars ventralis of the anterior olfactory nucleus.

The medioventral division of the lateral olfactory tract likewise exchanges fibers with the intermediate olfactory tract and scattered fascicles to pars posterior of the anterior olfactory nucleus. Other fascicles, with fibers from the medial olfactory tract, swing medially to the anterior continuation of the hippocampus and the septal area.

The larger part of the fascicles constituting the three divisions of the lateral olfactory tract do not distribute in the crus or the rostral hemisphere levels but unite into a single bundle. This bundle continues laterally and caudally beneath tuberculum olfactorium (fig. 13), to which it discharges fibers, and reaches the pyriform lobe region (fig. 14). Here fascicles enter the anterior amygdaloid area, the rostral end of the medial amygdaloid nucleus and the nucleus of the lateral olfactory tract. The available material did not show whether any fibers entered the central or cortical amygdaloid nuclei as Ariëns Kappers, Huber and Crosby ('36) and Humphrey ('36) have reported.

Medial olfactory tract. The medial olfactory tract of the macaque may be divided into a dorsomedial and a ventromedial division. The dorsomedial part (figs. 4, 5) arises from the olfactory formation above the dorsomedial eminence of the bulb. It consists of relatively lightlystaining fibers, terminating chiefly in the rostral end of pars dorsalis of the anterior olfactory nucleus. It thus corresponds to the dorsomedial olfactory tract described by Humphrey ('36) in the bat. A few of the fibers may pass directly into the dorsal olfacto-frontal tract and 
small fascicles run on the medial side of the crus to the anterior continuation of the hippocampus.

The ventromedial portion of the medial olfactory tract (fig. 4, 5, 11,12 ) arises from the medial and the ventromedial portions of the olfactory bulb to accumulate along the ventromedial angle of the crus. Laterally it is indistinctly separated from the medioventral portion of the lateral olfactory tract. This ventromedial portion travels caudally through the crus, to terminate in pars dorsalis and pars medialis of the anterior olfactory nucleus. Some of the fibers appear to pass upward to join the dorsal olfacto-frontal tract. Others, with fibers from pars medialis of the anterior olfactory nucleus, travel dorsally along the lateral side of gyrus rectus to a position ventral to the bundles previously described from the medioventral division of the lateral olfactory tract and enter the medial forebrain bundle with them. Other fascicles reach the same region by crossing through the cortex. Farther caudally, fibers from the medial side of the tract pass directly into the anterior continuation of the hippocampus. These are joined by small bundles from pars medialis of the anterior olfactory nucleus and by small fascicles from the lateral part of pars dorsalis of the same nucleus, which swing completely across the bulb to take a position on the medial side of pars medialis. The remaining fibers of the ventromedial division end either in pars posterior of the anterior olfactory nucleus or, with fibers from the medioventral division of the lateral olfactory tract, pass behind the frontal cortex to travel anterio-dorsally along the side of the ventral longitudinal fissure to the medial septal area.

Intermediate olfactory tract. The intermediate olfactory tract (figs. $5,11,12$ ) has its origin in the lateral and the ventrolateral olfactory formations, as does the medioventral division of the lateral olfactory tract. The fibers of these two tracts pass upward and caudally together, but those of the intermediate tract accumulate between the ependyma of the ventricle and the more superficial medioventral bundle. The two systems can be easily distinguished due to the lighter staining of the intermediate tract. In more caudal planes, there is a readily discernible row of neuroglia cells between them. The intermediate olfactory tract remains practically intact until the hemisphere is reached. It then exchanges fibers with the lateroventral division of the lateral olfactory tract, and with pars ventralis and pars lateralis of the anterior olfactory nucleus. As the lateral ventricle moves dorsally, the medial half of this tract swings upward and laterally to a position ventral to the junction of the putamen and the caudate nucleus. Here it is joined by fibers from the prepyriform area and by a few from 
tuberculum olfactorium. It then turns caudally to enter the anteroventral part of the anterior commissure. The lateral half of the intermediate tract continues caudally to distribute to the polymorph layer of the anterior end of tuberculum olfactorium.

\section{Olfacto-frontal connections}

Between the rostral tip of the anterior olfactory nucleus, and the ependyma of the obliterated ventricle of the crus lies a thin band of fibers, the dorsal olfacto-frontal tract (figs. 11, 12). Caudally, other fibers are added to the medial side of this tract from pars dorsalis and pars medialis of the anterior olfactory nucleus. There are some indications that a few fibers may pass directly into this bundle from the dorsal and the ventral divisions of the medial olfactory tract. The lateral side of the dorsal olfactory tract sends fascicles to pars lateralis and particularly to pars ventralis of the anterior olfactory nucleus. Soon after the crus joins the hemisphere, the dorso-frontal tract passes upward as a rather diffuse mass of fiber's to enter the overlying cortex (fig. 12). Many of these fibers turn laterally, directly below those from the rostrum of corpus callosum, to distribute to the deeper layers of the cortex, and even as far laterally as the pyriform lobe.

Beginning in planes through the area where the crus becomes attached to the hemisphere, there accumulates, between the lateral edge of the lateral olfactory tract and the lateral part of the olfactory sulcus, a considerable mass of very thinly medullated fibers (the lateral olfacto-frontal fascicles, figs. 11, 12). Some of these apparently come from the overlying neopallial cortex and others from pars dorsalis of the anterior olfactory nucleus, but the greater part originate in pars lateralis of the same nucleus. With the final closing of the olfactory sulcus, these fibers spread out laterally and rostrally to end in the plexiform layer of the cortex of the orbital gyri.

On the medial side of the caudal part of the crus, the thinly medullated medial olfacto-frontal fascicles (fig. 12) from pars dorsalis and pars medialis of the anterior olfactory nucleus and from the overlying cortex appear. These may possibly be joined by direct fibers from the medial olfactory tract. With the disappearance of the olfactory sulcus, they pass laterally, and particularly rostrally, to distribute thronghout the plexiform layer of gyrus rectus.

An olfacto-frontal tract in Ornithorhynchus (Hines, '29) and in the opossum (Herrick, '24 and Loo, '31) appears to pass to the medial hemisphere wall as part of the septo-cortical system (Herrick, '24). It is not comparable to the interconnections of the secondary olfactory 
centers and the frontal cortex as here described, although it may be a forerunner of this system. In the bat, Humphrey ('36, p. 656) suggested that a very limited number of the fibers of her dorsomedial olfactory tract passed to the frontal cortex, but apparently the system was not so well developed as in the macaque. In view of these facts, and of the even greater relative reduction of the olfactory system in the monkey as compared to the bat, one is inclined to consider the possible existence in the primates of fronto-olfactory as well as olfacto-frontal fascicles in these various connections between the frontal cortex and the anterior olfactory nucleus.

\section{The fornix system}

The fornix system has been figured and more or less completely described by nearly all students of the olfactory areas of the hemisphere and there are reviews of the pertinent literature in most neuroanatomical reference books (Edinger, '11, Ramón y Cajal, '11, Ariëns Kappers, Huber and Crosby, '36, and others). Attention should be called in particular to the pioneer work of Edinger and Wallenberg ('01) and Elliot Smith $(1896,1896 \mathrm{a}$ and $1897 \mathrm{a})$. Among recent accounts are those of Loo ('31), M. Young ('36) and Fox ('40).

The present account is concerned with fascicles of the precommissural and the postcommissural fornices in so far as they are related to the basal hemisphere centers under consideration. Consequently it begins with a description of these bundles as they appear near the rostral end of the medial hemisphere wall.

The precommissural fornix. The precommissural fornix (figs. 11-13, 15) is that portion of the fornix system which passes in front of the anterior commissure to its distribution. In the macaque its most rostral fibers appear between the body and rostrum of corpus callosum (fig. 11), but immediately caudally it is bordered laterally by the rostral end of the lateral septal muscles and ventrally by the anterior continuation of the hippocampus. From this position the precommissural fornix gives off a few fibers to the medial side of the lateral septal nucleus, after which it swings ventralward to undergo almost immediately a partial crossing. It then continues ventrocaudally to its various regions of distribution. As the fibers are traced caudalward in the hemisphere, they contribute first to the anterior continuation of the hippocampus. and then pass to the medial septal nucleus and, along the lateral border of this nucleus, to tuberculum olfactorium. Whether or not any of them become components of the diagonal band is uncertain, but some of them 
appear to join the medial forebrain bundle and become a part of it. Other fibers pass caudally to the preoptic and the hypothalamic areas.

The postcommissural fornix. The postcommissural fornix (figs. 14 to. 17) passes to its distribution by a path caudal to the anterior commissure and so has distinctly more limited relations to the basal hemisphere centers than does the precommissural portion. It does contribute some bundles to the caudal end of the lateral septal nucleus, which it borders medially, and probably to the septo-hippocampal nucleus. As it overlies the anterior commissure, fibers (probably collaterals in part) enter the bed nucleus of the anterior commissure and nucleus triangnlaris, chiefly its supracommissural portion (fig. 14). Behind the anterior commissure, the postcommissural fornix gives off some bundles to the preoptic area and then almost immediately breaks up into two major subdivisions. One of these turns dorsally to enter stria medullaris (fig. 15), constituting the so-called medial cortico-habenular tract. The remainder of the fibers proceed ventrocaudally (figs. 16, 17) to distribute to the hypothalamic areas, including the mammillary body, and possibly, after decussating, to midbrain regions. The details of its distribution to levels behind the telencephalon need not be considered here.

\section{Connections of septal areas}

For the last thirty-five years various papers concerned with the anatomy of the septum have been appearing in the literature. These analyses have involved the study of both submammalian and mammalian brains. Among those who have studied this region are: Herrick ('10), Johnston ('13 and '23), Crosby ('17), A. Young ('26), Huber and Crosby ('29), Craigie ('30), Loo ('31) and Fox ('40).

In the earlier portion of this paper the following nuclear groups were described in the septal area - lateral septal nucleus, medial septal nucleus, septo-hippocampal nucleus, nucleus accumbens, nucleus triangularis, and the bed nucleus of the anterior commissure. To the septal areas, the following fiber systems have been traced - fascicles of the medial olfactory tract, septo-tubercular and tuberculo-septal fibers, cortico-septal and septo-cortical components of the precommissural and the postcommissural fornix systems, fibers of the diagonal band of Broca, scattered bundles to the stria medullaris, and fascicles running in the medial forebrain bundle and to a limited extent, in stria terminalis. Thus the precommissural fornix has been followed to the lateral and to the medial septal nuclei, and the postcommissural fornix to the more caudal portion of the lateral septal nucleus, to the septo-hippocampal 
nucleus and to the bed nucleus of the anterior commissure. A direct olfactory contribution to the medial septal nucleus by way of the ventromedial division of the medial olfactory tract is clearly evident. Fibers from the medial and perhaps from the lateral olfactory tract connect with nucleus accumbens. No other direct olfactory tract fibers were traced to the septal region.

The medial forebrain bundle (figs. 13-17) is a somewhat complex system of fibers, interconnecting the tertiary olfactory basal areas of the medial part of the hemisphere wall with the preoptic and the hypothalamic centers. However, such bundles are supplemented by contributions from the precommissural fornix and from the olfactory bulb. In transverse planes through the rostral end of the lateral septal nucleus, nucleus accumbens and the anterior continuation of the hippocampus, bundles from the dorsolateral portion of the lateral olfactory tract, pars lateralis of the anterior olfactory nucleus, the prepyriform cortex (prepyriform component of the medial forebrain bundle) and the ventromedial division of the medial olfactory tract lie between nucleus accumbens and the frontal cortex. They are joined here by fascicles from the lateral septal nucleus. The small accumulation of fibers thus formed may be designated as the medial forebrain bundle. From this position the bundle proceeds almost directly caudally, joined by scattered fascicles from nucleus accumbens, possibly from the basal part of the caudate and from tuberculum olfactorium. The fibers from the tuberculum appear to be related, in part, with the islands of Calleja. As the caudal end of tuberculum olfactorium is approached, the diagonal band of Broca is practically inseparable from the medial forebrain bundle (fig. 14). Farther caudally, the medial forebrain bundle lies ventral to the anterior commissure along the ventromedial border of the internal capsule. Here it is in intimate relations with, and perhaps in synaptic connection with, the bed nucleus of the anterior commissure. Behind this commissure, the medial forebrain bundle distributes to the preoptic and hypothalamic centers.

One of the most striking connections of this septal area is the diagonal band of Broca (fig. 14). It will be remembered that the medial septal nucleus is not sharply differentiable from the rostro-medial portion of the nucleus of the diagonal band. This band inter-connects the medial septal area and tuberculum olfactorium on the one hand with the lateral hemisphere wall, including globus pallidus and the amygdala, on the other. The diagonal band passes from the ventral end of the medial septal nucleus to encroach on the caudal end of tuberculum olfactorium, which it gradually replaces from medial to lateral, and then proceeds 
to the lateral hemisphere wall. Here the more dorsal fibers swing into globus pallidus nd the more ventral bundles into the anterior amygdaloid area. Some of the latter can be traced back toward the rostral end of the medial amygdaloid nucleus.

From the lateral septal nucleus and possibly from other septal areas, such as the bed nucleus of the anterior commissure, fibers join the medial cortico-habenular component of the postcommissural fornix to pass back into stria medullaris. They constitute a septo-habenular component of the stria.

The bed nucleus of the anterior commissure receives collaterals and perhaps stem fibers from the amgdyala by way of the temporal pole component of the commissure and the precommissural portion of stria terminalis. The lateral septal nucleus and nucleus accumbens, and the medial septal nucleus and the septal portion of the nucleus of the diagonal band (fig. 13) are interconnected by rich internuclear fibers.

Tuberculum olfactorium is interconnected with the septal area by a rostral band which extends between the rostral end of tuberculum olfactorium and the frontal portion of the lateral septal nucleus and a more caudal bundle which connects more caudal portions of tuberculum olfactorium with the medial septal nucleus. Various accounts in the literature on submammalian and subprimate forms suggest that connections with the lateral septal nucleus may be largely septo-tubercular and those with the medial septal nucleus primarily tuberculo-septal (e.g., Crosby, '17).

\section{Connections of tuberculum olfactorium}

The connections of tuberculum olfactorium have already been mentioned with the exception of the tuberculo-amygdaloid component. It is evident that the tuberculum receives olfactory impulses by way of the lateral and the intermediate olfactory tracts. A definite distribution of the olfactory tracts to tuberculum olfactorium has been questioned by Beccari ('12) but has been substantiated by various other observers (e.g., Humphrey, '36). The tuberculum is also related to olfacto-cortical centers by way of the precommissural fornix. Its rostral portion is connected with the lateral septal nucleus and its caudal portion with the medial septal nucleus by the rostral and caudal tuberculo-septal tracts. Fascicles from the tuberculum are also components of the medial forebrain bundle. It apparently contributes fibers to the diagonal band of Broca and so is related to the amygdala by a tuberculoamygdaloid tract (Humphrey, '36, and others). 


\section{Anterior commissure}

Many workers (Ramón y Cajal, '11, Sonntag and Wollard, '25, Gurdjian, '25, Humphrey, '36, and M. Young, '36) have made extensive studies of the anterior commissure and the reports on its components vary according to the animal studied. In the present account three major divisions are recognized - the anterior, the transverse, and the ventral or temporal limbs of the commissure.

The anterior limb of the anterior commissure. The fascicles which comprise this bundle come from the more rostral part of the basal areas of the hemisphere and pass caudalward between tuberculum olfactorium and the striatum. The bulbar contribution, as previously mentioned, arises from the medial half of the intermediate olfactory tract and thus largely from the olfactory formation, although joined by fascicles from the anterior pyriform area. Ramón y Cajal ('11) stated that this component of the anterior commissure consists of interbulbar fibers. M. Young ('41 and '42), from his experimental studies, came to the conclusion that, in the rabbit, the interbulbar fibers arise not from the mitral cells, but from that portion of the anterior olfactory nucleus which he regarded as a forward extension of the prepyriform area into the bulb.

Farther laterally two other smaller bundles of the anterior limb of the commissure pass caudally in the deeper part of tuberculum olfactorium (fig. 13). These are principally from the anterior pyriform area but also contain some fibers from the external capsule, as was reported by M. Young ('36) in the rabbit. Fine pale-staining fibers from the tuberculum can be traced to the two medial bundles and, in all likelihood, are also present in the more lateral bundle. These fibers do not form a separate component as in the bat (Humphrey, '36). It was interesting to note that a small island of Calleja was associated with each of these three bundles. There also appears on the superficial surface of tuberculum olfactorium, directly below each of these divisions, a large triangular-shaped island from which fine fibers pass upward toward the overlying tracts (fig. 13). As the anterior commissure is approached, the three divisions of the anterior limb swing dorsally and medially to occupy the anteroventral part of the commissure.

The transverse limb of the anterior commissure (figs. 14, 15) This is the largest of the three portions of the commissure. It extends farther laterally than do the other components, to spread out in the external capsule and so to distribute to the neopallial cortex of the lateral wall. Although fascicles of the internal capsule can be seen running 
between the fibers of this division, where the two tracts cross there was no indication that any fibers of the internal capsule actually join the anterior commissure, as has been reported by Elliot Smith ('02) in diprotodonts and Humphrey ('36) in the bat, nor were any fibers found to join it from the putamen, such as were reported by Loo ('31) for the opossum.

The ventral or temporal limb of the anterior commissure (fig. 15). This division occupies the posterior part of the commissure. It passes laterally and caudally with the transverse limb to the region of the putamen. Here the fibers swing laterally, partly between the putamen and the amygdala and partly through the ventral part of the putamen, to pass down the lateral side of the lateral amygdaloid nucleus to the pyriform area. This ventral division receives fibers from the lateral and the basal amygdaloid nuclei as well as from the pyriform area. Undoubtedly some fibers also. enter it from the external capsule.

\section{Connections of the amygdaloid complex}

The amygdala is made up of a series of nuclear groups which, from the standpoint of their phylogeny, embryological development, adult nuclear pattern and fiber connections, consist of more than a single entity. Johnston ('23), Berkelbach van der Sprenkel ('26), M. W. Young ('36), Humphrey ('36) and Fox ('40) have studied the mammalian amygdala extensively. Of these, the most detailed account is that of Berkelbach van der Sprenkel. The connections here deseribed are recognizable in normal Weil preparations. The structural and functional significance of this area has never been entirely explained and the present account affords a point of departure for future experimental investigation.

The study of the Weil preparations of the macaque brain permitted the identification of the following amygdaloid connections (figs. 15-17): (1) components in the temporal limb of the anterior commissure, (2) stria terminalis, (3) the amygdalo-hypothalamic tract, (4) the lateral olfactory tract, (5) inter-connections between the cortex and the amygdaloid groups, (6) fascicles from the diagonal band of Broca, and (7) the so-called longitudinal bundle. The amygdaloid components of the lateral olfactory tract and the anterior commissure, and the tuberculoamygdaloid fascicles of the diagonal band have already been described and that description need not be repeated here.

Stria terminalis. The stria terminalis (figs. 15-17) has several interesting features in the macaque. Within the amygdaloid nucleus two 
main fascicles enter this bundle. The medial fascicle is formed by two groups of fibers, one of which is apparently in connection with the cortical, the medial and the central amygdaloid nuclei and the other with the basal and the basal accessory amygdaloid nuclei. The fibers from these two parts become a definite bundle in the caudal half of the amygdaloid complex and pass upward along the dorsomedial surface of the inferior horn of the lateral ventricle (fig. 17) to assume a position on the medial border of the caudate nucleus. In this dorsocaudal course, they pass through the caudal end of the anterior amygdaloid area where fibers are added. Then this component of the stria is joined by the lateral component. This latter portion can be traced from the under side of the basal amygdaloid and the lateral amygdaloid nuclei and from the inner border of the pyriform cortex to a position below the ventricle. From here it curves upward along the outer border of the ventricle to reach the ventrolateral surface of the caudate nucleus (fig. 16). It then passes over the dorsal surface of this nucleus (fig. 17) to join the medial component on the medial side of this gray mass. These two components are distinguishable from each other, even after uniting in stria terminalis, because of their differential staining. In the Weil material, the lateral component is made up of rather coarse, darkstaining fascicles which contrast with the finer, lighter-staining fibers of the medial group.

After its formation by these two components, stria terminalis continues along the caudate nucleus to the level of the anterior commissure. Throughout this extent, the medial and the lateral components maintain their integrity and the same relative position to each other and to the caudate nucleus. Due, however, to the fact that the caudate follows the curve of the ventricle, the dorsoventral relation of these components is reversed. Thus the lateral portion, which lies dorsomedial in the amygdaloid region, lies ventromedial to the medial component at the level of the anterior commissure. As the bed nucleus of stria terminalis appears, the components can be still further differentiated from each other since the medial portion lies dorsal to the bed nucleus and the lateral portion ventromedial to it (fig. 15).

In the region of the anterior commissure, fibers of the medial division pass in front of the commissure to preoptic and probably to hypothalamic areas, constituting the so-called precommissural component of the stria. Other fascicles from the medial component form the commissural component of the stria, and still others break up in the bed nucleus of the anterior commissure. The remaining fibers of this component collect immediately above the posterior portion of the anterior 
commissure as the supracommissural portion of the stria, from which position they distribute, behind the commissure, to the preoptic and hypothalamic areas.

The lateral component of stria terminalis (fig. 15) swing's ventrocaudally behind the anterior commissure. This ventrocommissural or postcommissural part gives off the amygdalo-habenular component which, at the transition region of the diencephalon enters the accumulating stria medullaris. The remainder of the lateral fibers pass caudally into the dorsal part of the hypothalamic area. They appear to pass to the dorsal hypothalamic area and adjacent regions but this requires verification.

The foregoing components were distinguishable in Weil preparations. Probably they do not represent all of the amygdaloid components of stria terminalis. In the material studied it was not possible to demonstrate the commissural component of the stria which, in most mammals, and probably also in the macaque, inter-connects the nuclei of the lateral olfactory tract of the two sides. Certain observers have considered this bundle to be unmedullated and perhaps that accounts for the inability to demonstrate the connection in the available material. Stria terminalis may carry bundles which are both afferent and efferent with respect to the amygdaloid complex, although this is not in line with certain experimental results obtained by Fox ('43) in the cat. It has been convenient to describe them here as passing from the amygdala to the preoptic and hypothalamic areas.

The longitudinal bundle. The longitudinal bundle, described by various observers (Johnston, '23, and Fox, '40), has been identified in the macaque. This tract has never been satisfactorily analyzed and since the available material permits no additions to the present knowledge of its course and relations, it is not described here, although its position is indicated in figures 15 and 16.

Amygdalo-hypothalamic tract. In addition to amygdalo-hypothalamic components of stria terminalis, more directly running fascicles from the cortico-medial portion of the amygdala and from the anterior amygdaloid area pass directly medially, ventral to the internal capsule, to preoptic and hypothalamic areas (fig. 16). They correspond to the ventral olfactory projection tract described for various submammals (Crosby, '17, Crosby and Woodburne, '40).

Amygdalo-cortical connections. There is some evidence that the amygdala is related to the overlying cortex, particularly its basolateral part. Such connections have also been reported by other observers. 


\section{GENERAL SUMMARY AND DISCUSSION}

The olfactory bulb of the macaque is small, with a fairly long, slender crus. Microscopic preparations indicate that the layer arrangement in the bulb is that typical for mammals. On the basis both of nuclear configuration and of distribution of the incoming olfactory fila, it shows a secondary subdivision into dorsal, medial, ventral and lateral sectors. It is hoped at some future time to test experimentally whether these sectors are an indication of a localization pattern for entering olfactory impulses similar to that found in the brain for other sensory systems.

The accessory bulb may be lacking or may be present in the macaque. In those cases in which it was identified in the available material, it was present only on the left side. These relations are in line with its presence in the human embryo (Humphrey, '40) and its absence in adult man. The mitral cells of the olfactory bulb contribute to the lateral, the medial and the intermediate olfactory tracts. If an accessory olfactory bulb is present, its mitral cells send their neuraxes into the dorsolateral division of the lateral olfactory tract. It is generally recognized that the accessory bulb receives fibers from the vomeronasal nerve (McCotter, '12).

The anterior olfactory nucleus, as might be expected in a form with a small olfactory formation, is not highly developed but it is better differentiated than in man. It shows bulbar, crural and hemispheric portions. The bulbar portion is represented by a small group of cells appearing dorsal to the ventricle in planes just caudal to the accessory olfactory bulb. This dorsal group is not continuous with the crural part of the anterior olfactory nucleus. Throughout nearly the whole extent of the crus, there is a small but quite definite pars dorsalis of the anterior olfactory nucleus, which passes back into the hemisphere to merge with the neopallial cortex. This pars dorsalis receives fibers from the lateral and the medial olfactory tracts and fascicles from it join the olfacto-frontal tracts. It also conributes to the lateral olfactory tract.

Pars medialis, pars lateralis and particularly pars ventralis of the anterior olfactory nucleus are poorly developed in the rostral two-thirds of the crus, being represented only by small clusters of cells or often, in the ease of pars ventralis, by single neurons. As the crus grades over into the hemisphere, these portions of the anterior olfactory nucleus become better represented, but at no level does this nucleus form a ring of gray around the ventricle as is the case in various other vertebrates (Herrick, '24, Obenchain, '25, and others). Within the hemisphere, pars ventralis passes over into tuberculum olfactor- 
ium, pars lateralis into the cortex of the prepyriform area, and pars medialis into the anterior continuation of the hippocampus. Each of these portions of the anterior olfactory nucleus is connected with the area with which it is continuous by internuclear fibers which run in company with the associated olfactory tracts. Each receives olfactory tract fibers. In addition pars lateralis contributes fibers to the medial forebrain bundle, to nucleus accumbens and possibly sends fascicles to the anterior commissure. Pars ventralis sends fibers to the dorsal olfactofrontal tract and from pars medialis fascicles pass toward the septal region. It is to be understood that, for the present, these tracts have been described as if they were passing caudally from the anterior olfactory nucleus. It is very likely that some of them also carry afferent bundles to the various parts of the nucleus.

The tuberculum olfactorium shows the usual relationships to the surrounding areas. It is least well developed in the rostral third where the typical layers - molecular, pyramidal and polymorph - are differentiable only on the lateral side. The islands of Calleja are typical but small. The medial island is composed almost entirely of granule cells except for small pockets which enclose scattered, large neurons. The remaining islands are chiefly of the granular type but with some pyramidal cells present. The tuberculum olfactorium receives fibers from the lateral and the intermediate olfactory tracts. Fascicles from the medial forebrain bundle both enter and leave this nucleus. It is interconnected with the hippocampal cortex by way of the precommissural fornix and with the septal area by fibers which accompany the diagonal band of Broca. A small component was traced from the tuberculum to the anterior commissure and an interconnection with the amygdala has been demonstrated.

In the septal region of the hemisphere, the following nuclei were identified - the lateral and the medial septal nuclei, the septo-hippocampal nucleus, nucleus accumbens, nucleus triangularis, nucleus of the diagonal band of Broca and the bed nuclei of the anterior commissure and of stria terminalis. Of the nuclear masses of this region, the lateral septal nucleus has the greatest extent, being present throughout the entire region. It is bordered medially, first by the precommissural fornix and then by the fornix proper, from both of which it receives fibers. It contributes fibers to the medial forebrain bundle and to tuberculum olfactorium and has short internuclear connections with nucleus accumbens.

The medial septal nucleus is of much less extent than the lateral nucleus and is indistinguishable ventrocaudally from the nucleus of the 
diagonal band of Broca. Fibers from the medial forebrain bundle enter this nucleus and it is connected with the hippocampus by fascicles (probably septo-hippocampal fibers) which rum with the precommissural fornix. Fascicles from the medial olfactory tract enter its superficial border in small amount. Possibly one of its most significant connections is that with the lateral part of the hemisphere by way of the diagonal band.

The septo-hippocampal nucleus is represented by clusters of cells which extend along a line passing beneath corpus callosum from the anterior continuation of the hippocampus rostrally to the hippocampus proper caudally where it lies under the splenium of corpus callosum. In none of the series studied, can it be traced as a continuous band of cells as M. Young ('36) was able to do in the rabbit and Humphrey ('36) in the bat. This failure to appear as a continuous band is probably due to the greater stretching of the septal area in primates through the development of a larger corpus callosum.

Nucleus accumbens is quite well developed in the macaque. Besides internuclear connections with surrodnding areas - the septal area, the caudate nucleus and tuberculum olfactorium - it is in functional relationship with the medial forebrain bundle. The bed nucleus of the anterior commissure, in addition to contributions to and from the medial forebrain bundle, receives collaterals and terminal fibers of various components passing through the anterior commissure and collaterals and stem fibers of stria terminalis, particularly its supracommissural component. Specific connections of nucleus triangularis, other than possible fibers from the fornix, have not been demonstrated. One relation of this nucleus might be emphasized. It lies chiefly rostral to the anterior commissure but extends caudalward for a short distance both above and below these fibers.

The nucleus of the diagonal band of Broca belongs only in part to the septal area. Beginning as a caudoventral continuation of the medial septal nucleus, it continues ventralward and then almost directly lateralward across the caudal side of tuberculum olfactorium, to reach the substriatal regions of the hemisphere. Here it spreads out in two major strands, one of which is directed toward globus pallidus and the other toward the anterior amygdaloid area. This group of cells is an interstitial nucleus for the accompanying diagonal band of Broca. No one as yet has completely analyzed the various connections of this fiber bundle but, in general, it serves to interconnect the septal areas of the hemisphere with its striatal and amygdaloid regions. 
The amygdaloid complex shows marked resemblance to that described for man, the differences being those which are primarily due to the comparative degree of development and shifts in the temporal pole (Crosby and Humphrey, '44). For purposes of description, the amygdala has been divided into an anterior amygdaloid area, a corticomedial group and a baso-lateral group. The anterior amygdaloid area receives fibers of the lateral olfactory tract, contributes fascicles to stria terminalis and to the diagonal band of Broca, and is one of the regions of origin for the amygdalo-hypothalamic tract. The corticomedial group of the amygdala receives lateral olfactory tract fibers, is concerned in the formation of the medial division of stria terminalis and contributes to the amygdalo-hypothalamic tract.

The baso-lateral amygdaloid group makes a large contribution to the anterior commissure. Fibers from the dorsal part of the basal and the basal accessory nuclei join those of the cortico-medial group in the medial division of stria terminalis. In the ventral portion of the same two nuclei, other fibers accumulate to enter the lateral component of stria terminalis. No olfactory tract fibers have been traced to this portion of the amygdala. Interconnections with the overlying cortex have been demonstrated for the baso-lateral group. The so-called longitudinal bundle has been traced from the lateral amygdaloid nucleus (and possibly from the basal) to a position below globus pallidus. It could not be followed beyond this point in the available material.

The foregoing study of selected basal centers of the telencephalon of the macaque indicates, in general, their conformity with the pattern characterizing the comparable regions in subprimates. These centers, however, both in their degree of development and in the differences in the size of their related fiber connections, show modifications of the subprimate pattern. An appreciation of these differences is significant for an understanding of the normal anatomy of these regions and is necessary for the contemplated experimental studies.

\section{LITERATURE CITED}

Ariéns Kappers, C. U., G. C. Huber AND E. C. Crosby 1936 The comparative anatomy of the nervous system of vertebrates, including man. The Macmillan Co., New York.

BecCari, N. 1910 Il lobo parsolfattorio nei mammiferi. Arch. Ital. di Anat. e di Embriol., vol. 9 , pp. $173-220$.

1912 La sostanza perforata anteriore e $i$ suoi rapporti col rinencefalo nel cervello dell 'uomo. Arch. Ital. di Anat. e di Embriol., vol. 10, pp. 261-328.

Berkelbach VAN DER SPRenKeL, H. 1926 Stria terminalis and amygdala in the brain of the oppossum (Didelphis virginiana). J. Comp. Neur., vol. 42, pp. 211-254.

CRAigre, E. H. 1930 Studies on the brain of the kiwi (Apteryx australis). J. Comp. Neur., vol. 49, pp. 223-357. 
Crosbx, E. C. 1917 The forebrain of Alligator mississippiensis. J. Comp. Neur., vol. 27, pp. 325-402.

Crosbr, E. C., AND T. Humphrey 1939 Studies of the vertebrate telencephalon. I. The nuclear configuration of the olfactory and accessory olfactory formations and the nucleus olfactorius anterior of certain reptiles, birds and mammals. J. Comp. Neur., vol. 71 , pp. 121-213.

1941 Studies. II. The nuclear pattern of the anterior olfactory nucleus, tuberculum olfactorium and the amygdaloid complex in adult man. J. Comp. Neur., vol. 74 , pp. 309-352.

1944 Studies. III. The amygdaloid complex in the shrew (Blarina brevicauda). J. Comp. Neur., vol. 81, pp. 285-305.

Crosix, E. C., AND R. T. WoodBurne 1940 The comparative anatomy of the preoptic area and the hypothalamus. Res. Publ. Ass. Nerv. Ment. Dis., vol. 20, pp. 52-169.

EDINGER, L. 1911 Vorlesungen über den Bau der nervösen Zentralorgane des Menschen und der Tiere. Vogel, Leipzig.

Edinger, L., AND A. Wallenberg 1901 Untersuchungen über den Fornix und das Corpus mammillare. Archiv. f. Psychiat. u. Nerven., Bd. 35, s. 1-21.

Eldion SMinh, G. 1896 Morphology of the true "limbic lobe," corpus callosum, septum pellucidum and fornix. J. Anat., vol. 30, pp. 185-205.

1896a The fornix superior. J. Anat. and Physiol., vol. 31, pp. 80-94.

1897 The origin of the corpus callosum. Tr. Linnean Soc. London, Ser. 2, vol. 7, pp. $47-70$.

$1897 \mathrm{a}$ The relation of the fornix to the margin of the cerebral cortex. J. Anat. and Physiol., vol. 32, pp. 23-58.

1902 On a peculiarity of the cerebral commissures in certain Marsupiala not hitherto recognized as a distinetive feature of the Diprotodontia. Proc. Roy. Soc. London, vol. 70, pp. 226-231.

1903 Zuckerkandl on the phylogeny of the corpus callosum. Anat. Anz., Bd. 23 , S. $384-390$.

Fox, C. A. 1940 Certain basal telencephalic centers in the eat. J. Comp. Neur., vol. 72, pp. $1-62$.

1943 The stria terminalis, longitudinal association bundle and precommissural fibers in the eat. J. Comp. Neur., vol. 79, pp. 277-295.

GURDJIAN, E. S. 1925 Olfactory connections in the albino rat, with special reference to the stria medullaris and the anterior commissure. J. Comp. Neur., vol. 38, pp. 127-163.

1927 The diencephalon of the albino rat. Studies on the brain of the rat. No. 2, J. Comp. Neur., vol. 43, pp. 1-114.

HerRICK, C. J. 1910 The morphology of the forebrain in Amphibia and Reptilia. J. Comp. Neur., vol. 20, pp. 413-547.

1924 The nucleus olfactorius anterior of the opossum. J. Comp. Neur., vol. 37, pp. 317-359.

1933 The amphibian forebrain. VI Necturus. J. Comp. Neur., vol. 58, pp. 1-288.

HILPFRT, P. 1928 Der Mandelkern des Mensehen. I. Cytoarehitektonik und Faserverbindungen. J. f. Psychol. u. Neurol., Bd. 36, S. 44-74.

Hrnes, Marion 1929 The brain of Ornithorhynchus anatinus. Phil. Trans. Roy. Soc. London, Ser. B, vol. 217, pp. 155-287.

HUber, G. C. 1927 New method of fixation and staining of the central nervous system for purpose of study of cytoarchitecture. Contrib. to Med. Sci., Univ. of Michigan, dedieated to Aldred Seott Warthin. G. Wahr, Ann Arbor, Mich.

HuBER, G. C., AND E. C. CROSBY 1929 The nuclei and fiber paths of the avian diencephalon, with consideration of telencephalic and certain mesencephalic centers and connections. J. Comp. Neur., vol. 48, pp. 1-225. 
Humphrey, T. 1936 The telencephalon of the bat. I. The non-cortical nuclear masses and eertain pertinent fiber conriections. J. Comp. Neur., vol. 65, pp. 603-711.

1940 The development of the olfactory and the accessory olfactory formations in human embryos and fetuses. J. Comp. Neur., vol. 73, pp. 431-468.

JoHnston, J. B. 1913 The morphology of the septum, hippocampus, and pallial commissures in reptiles and mammals. J. Comp. Neur, vol. 23, pp. 371-478.

1923 Further contributions to the study of the evolution of the forebrain. J. Comp. Neur., vol. $35, \mathrm{pp}, 337-481$.

Loo, Y. T. 1931 The forebrain of the opossum, Didelphis virginiana. Pt. II. J. Comp. Neur., vol. 52, pp. 1-148.

McContek, R. E. 1912 The connections of the vomeronasal nerve and the accessory olfactory bulb in the opossum and other mammals. Anat. Rec., vol. 6, pp. 299-318.

Metrter, F. A. 1942 Neuroanatomy. C. V. Mosby Co., St. Louis, Mo.

Obenchain, J. B. $1925^{\circ}$ The brains of the South American marsupials Caenolestes and Orolestes. Publ. 224 of Field Museum of Natural History, Zool. Ser., vol. 14, pp. $175-232$.

Ramón y Cajal, S. 1911 Histologie du système nerveux de l'homme et des vertébrés. Vol. 9. A. Maloine, Paris, 2 vol.

RILEY, H. A. 1943 An atlas of the basal ganglia, brain stem and spinal cord based on myelin-stained material. The Williams and Wilkins Co., Baltimore, Md.

Sonntag, C. F., AND H. H. Woollard 1925 A monograph of Orycteropus afer. II. Nervous system, sense organs and hairs. Proc. Zool. Soc, London, vol. 2, pp. 1185-1235.

Vörsch, M. 1910 Zur vergleichenden Anatomie des Mandelkerns und seiner Nachbargebilde. II. Teil. Areh. f. mikr. Anat., Bd. 76, S. 373-523.

Young, A. W. 1926 The comparative anatomy of the septum pellucidum. Psychiat. en Neurol. Bl., vol. 30, pp. 203-234.

Young, M. W. 1936 The nuelear pattern and fiber commections of the non-cortical centers of the telencephalon of the rabbit. Huber Memorial Volume, J. Comp. Neur., vol. 65, pp. $295-401$.

1939 The fiber connections of the aceessory olfactory bulb of the rabbit (Lepus (uniculus). Anat. Ree., vol. 73, Supplement no. 2, p. 58. Abstract of paper presented at meeting Am. Assn. Anat., Boston, Mass., Apr. 6-8.

1941 Degeneration of the fiber tracts following experimental transection of the olfactory bulb. Anat. Rec., vol. 79, Supplement no. 2, pp. 65-66, Abstract of paper presented at meeting Am. Assn. Anat., Chicago, Tll., Apr. 9-11.

1942 Further studies on the interbulbar fibers. Anat. Ree, vol. 82, p. 480. Abstract of paper read by title at meeting of Am. Assn. Anat., New York, N. Y., Apr. 1-3. 


\section{ABBREVIATIONS}

A.PREOP., preoptic area

ANS.LENT.P.VENT., ventral part of ansa lenticularis

ANT.AMYG.A., anterior amygdaloid area

ANT.CONT.HIP., anterior continuation of hippocampus

BULB OLF.ACC., accessory olfactory bulb

CAP.INT., internal capsule

CAP.EXT., external eapsule

CH.OP., optic chiasma

CLALS., elaustrum

COM.ANT., anterior commissure

COM.ANT.L.ANT, anterior limb of anterior commissure

COM.ANT.L.TEMP., temporal limb of anterior commissure

COM.ANT.L.TRANS., transverse limb of anterior commissure

COM.MEY., commissure of Meynert

CORP.CAL., eorpus eallosum

CORP.CAL.ROS., rostrum of corpus callosum

CORT.AMYG.TR.A., cortico-amygdaloid transition area

CORT.PREPYR., prepyriform cortex

CORT.PYR., pyriform cortex

D.B.B.AND NUC, diagonal band of Broca and nucleus

EP., ependyma

FASC.LENT., fasciculus lenticularis

FIL.OLF., olfactory fila

FOR., fornix

FOR.POSTCOM., posteommissural fornix

FOR.PRECOM., precommissural fornix

GL.PAL., globus pallidus

G.ORB., orbital gyrus

G.RECT., gyrus rectus

HIP., hippocampus

IND.GR., indusium griseum

ISL.CAL., island of Calleja

ISL.CAL.M., medial island of Calleja

L.B., longitudinal bundle

L.GLOM., glomerular layer

L.GRAN.EXT., extrenal granular layer

L.GRAN.INT., internal granular layer

L.MIT.C., mitral cell layer

L.MOL.EXT., external molecular layer

M.INTER., interealate mass

M.F.B., medial forebrain bundle

NUC.ACC., nucleus accumbens

NUC.AMYG.BAS., basal amygdaloid nucleus

NUC.AMYG.BAS.ACC.P.LAT, lateral part of accessory basal amygdaloid nucleus
NUC.AMYG.BAS.ACC.P.MED., medial part of accessory basal amygdaloid nucleus

NUC.AMYG.BAS.P.LAT., lateral part of basal amygdaloid nucleus

NUC.AMYG.BAS.P.MED, medial part of basal amygdaloid nucleus

NUC.AMYG.BAS.P.MED.(D.), deep portion of medial part of basal amygdaloid nucleus

NUC.AMYG.BAS.P.MED.(S.), superficial portion of medial part of basal amygdaloid nucleus

NUC.AMYG.CENT., central amygdaloid nucleus

NUC.AMYG.CORT., cortical amygdaloid nucleus

NUC.AMYG.CORT.P.DOR., dorsal part of cortical amygdaloid nucleus

NUC.AMYG.CORT.P.VENT., ventral part of cortical amygdaloid nucleus

NUC.AMYG.LAT, lateral amygdaloid nucleus

NUC.AMYG.MED., medial amygdaloid nucleus

NUC.CAUD., caudate nucleus

NUC.COM.ANT., bed nueleus of anterior commissure

NUC.D.B.B., nucleus of the diagonal band of Broea

NUC.OLF.ANT.P.DOR., dorsal part of anterior olfactory nucleus

NUC.OLF.ANT.P.LAT., lateral part of anterior olfactory nucleus

NUC.OLF.ANT.P.MED., medial part of anterior olfactory nueleus

NUC.OLF.ANT.P.POST., posterior part of anterior olfactory nucleus

NUC.OLF.ANT.P.VENT., ventral part of anterior olfactory nucleus

NUC.SEPT.LAT., lateral septal nueleus

NUC.SEPT.MED., medial septal nueleus

NUC.ST.TERM., bed nucleus of stria terminalis

NUC.SUBTHAL., subthalamic nucleus

NUC.SUPRAOP., supraoptic nucleus

NUC.TRIANG., nuelens triangularis

NUC.TR.OLF.LAT.P.ANT., anterior part of nucleus of lateral olfactory tract

NUC.TR.OLF.LAT.P.POST, posterior part of nucleus of lateral olfactory tract

OLF.FR.FASC.LAT., lateral olfacto-frontal fascieles 
OLF.FR.FASC.MED., medial olfacto-frontal fascicles

PUT, putamen

ST.MED, stria medullaris

ST.TERM.P.LAT., lateral part of stria terminalis

ST.TERM.P.MED, medial part of stria terminalis

SUB.INOM., substantia innominata

TR.A., transition area between pyriform cortex and cortical amygdaloid nucleus

TR.A MYG.HYPO., amygdalo-hypothalamie

TR.CORT.HAB.MED., medial cortico-habenular tract

TR.MAM.THAL,mammillo-thalamic tract

TR.OLF.FR.DOR., dorsal olfacto-frontal tract

TR.OLF.INTER., intermediate. olfactory tract

TR.OLF.LAT,, lateral olfactory tract.

TR.OLF.LAT.P.DOR.LA'T., dorsolateral part of lateral olfactory tract
TR.OLF.LAT.P.LAT.VENT., lateroventra) part of lateral olfactory tract

TR.OLF.LAT.P.MED.VENT., medioventral part of lateral olfactory tract

TR.OLF.MED.P.DOR.MED., dorsomedial part of medial olfactory tract

TR.OLF.MED.P.VENT.MED., ventromedial part of medial olfactory tract

TR.OP., optic tract

TUB.OLF., tuberculum olfactorium

TUB.OLF.L.PLEX., plexiform layer of tuberculum olfactorium

TUB.OLF.L.POLY., polymorph layer of tuberculum olfactorium

TUB.OLF.L.PYR., pyramidal layer of tuberculum olfactorium

TR.A., transition area

V.III, third ventricle

V.LAT., lateral ventricle

ZONA INC., zona incerta

\section{PLATES 1 TO 8}

EXPLANATION OF FIGURES

1 to 5 Photomicrographs of transverse sections through the olfactory bulb and crus of the macaque. Figures 1 to 3 are from toluidin blue preparations and show the nuclear pattern. Figures 4 and 5, from Weil preparations, indicate the main fiber tracts. $\times 12$.

6 Photomicrograph through the precommissural septal region and the tuberculum olfactorium. Toluidin blue preparation. $\times 12$.

7 to 10 Photomierographs of a series of transverse sections through the amygdaloid complex of the macaque brain. These pictures form a rostrocaudal series designed to show the extent, the changing relations and the variations in size and appearance of the component nuclear groups. Toluidin blue preparations. $\times 12$.

11 and 12 Photomierographs through the rostrum of corpus callosum showing the relations, at these levels, of the olfactory tracts to various parts of the anterior olfactory nucleus. Weil preparations. $\times 8$.

13 Photomicrograph through the midportion of tuberculum olfactorium and the precommissural septal area of the macaque brain. Attention is directed particularly to the accumulating bundles of the anterior limb of the anterior commissure. Weil preparations, $\times 8$.

14 Photomicrograph through the rostral half of the anterior commissure. Nacaque material. Weil preparation. $\times 8$.

15 to $17^{\cdot}$ Photomicrographs through the amygdaloid region of the macaque brain. The figures also illustrate certain connections of the fornix. Weil preparations. $\times 8$. 


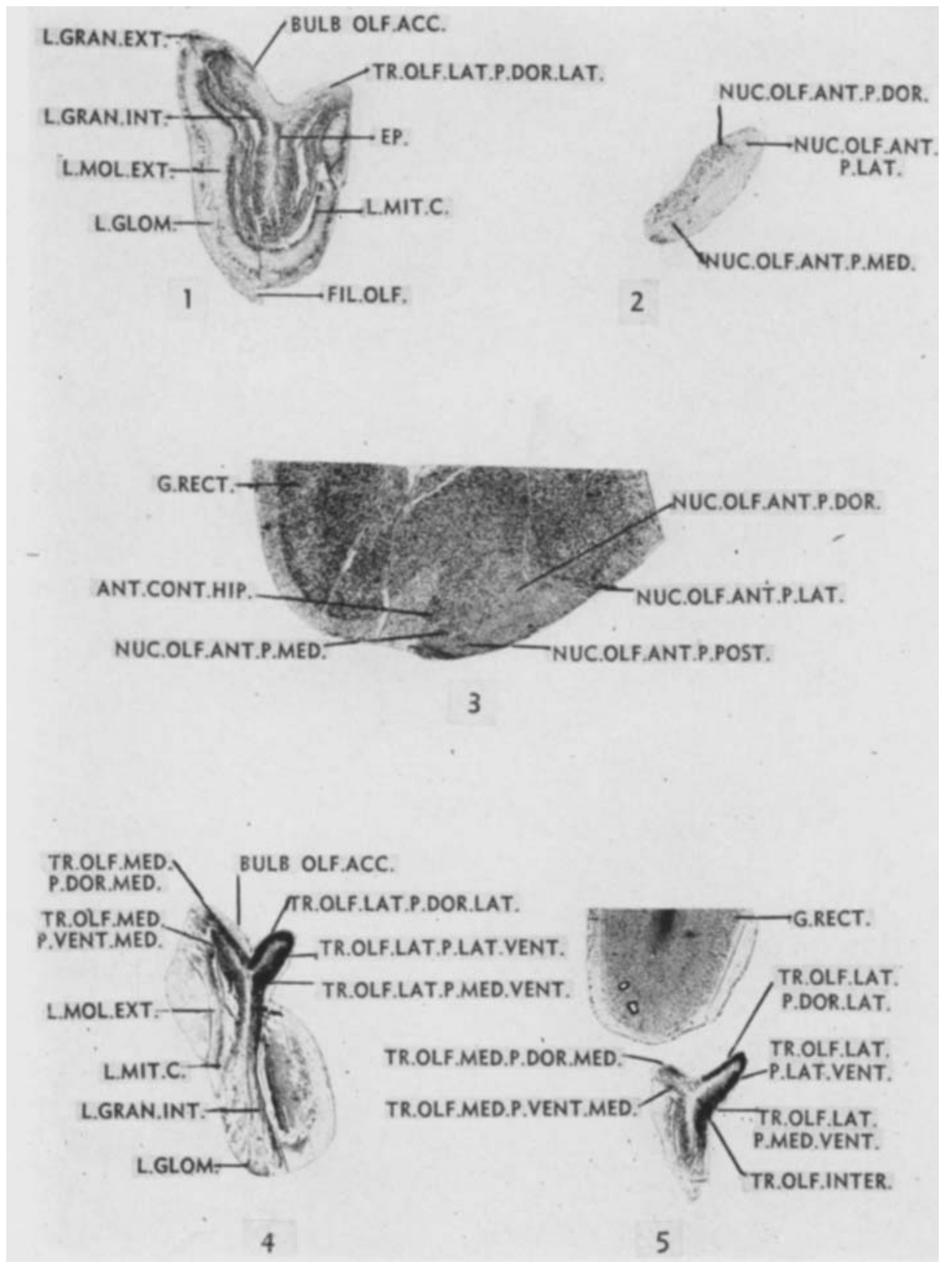




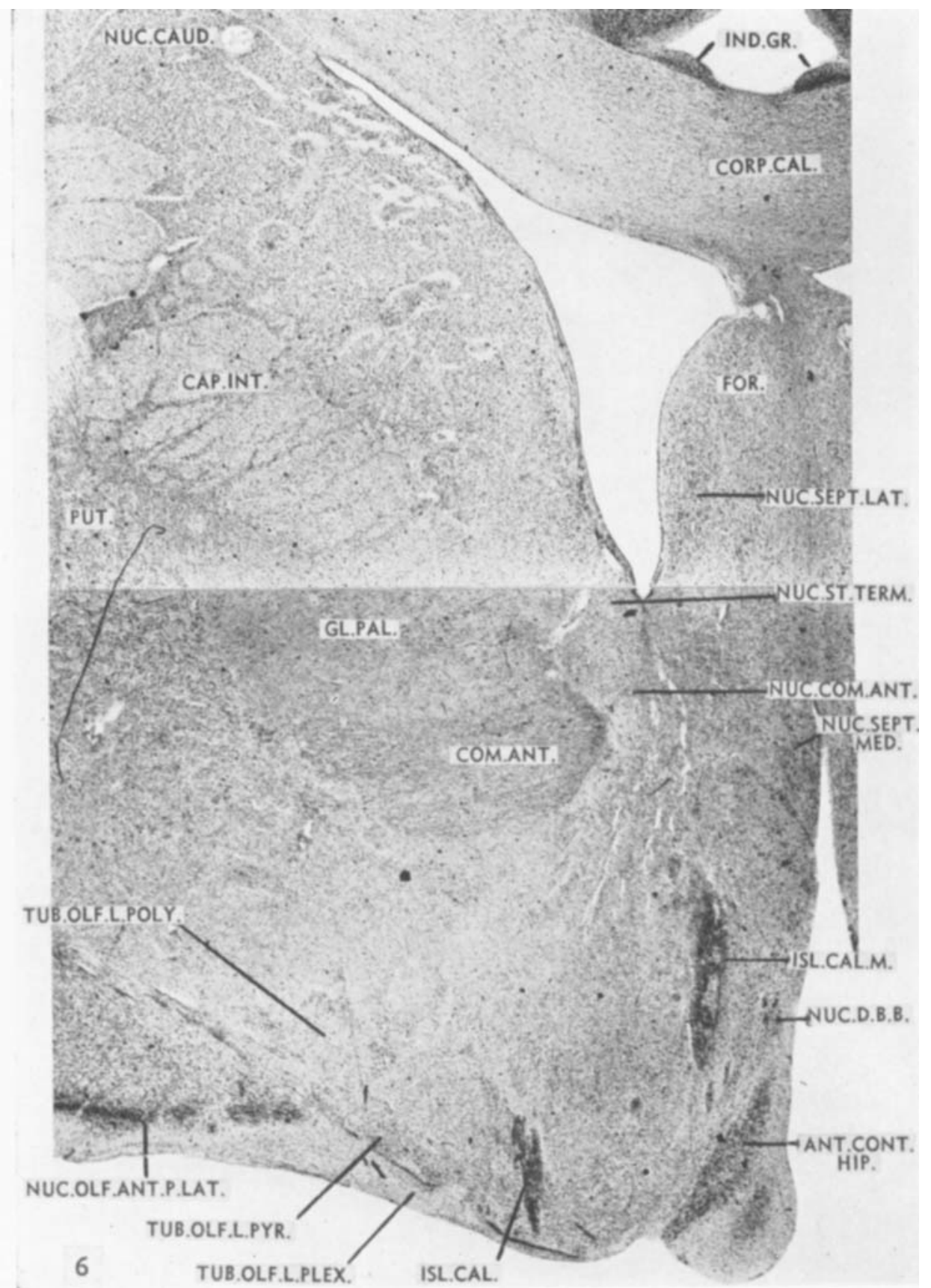




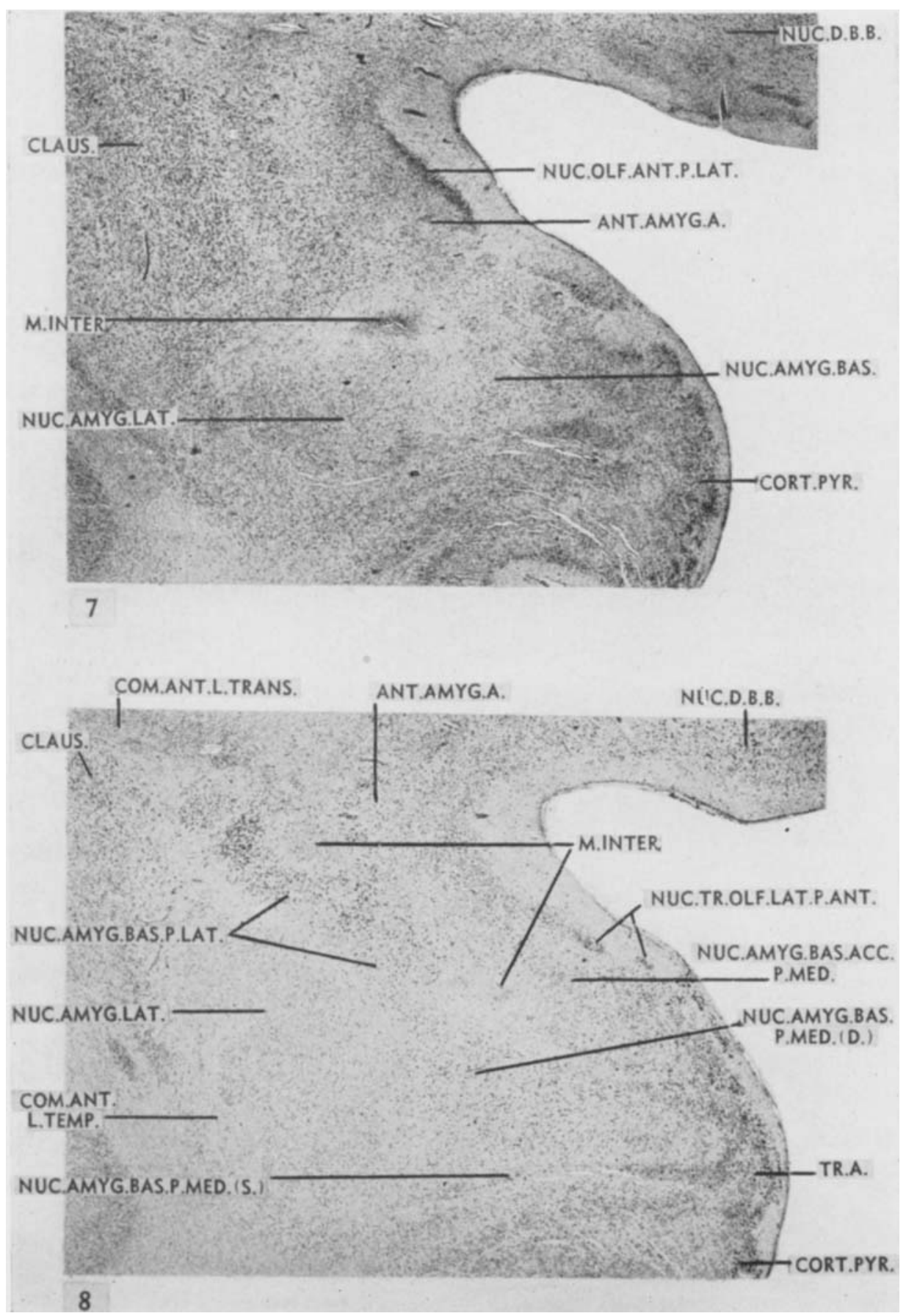




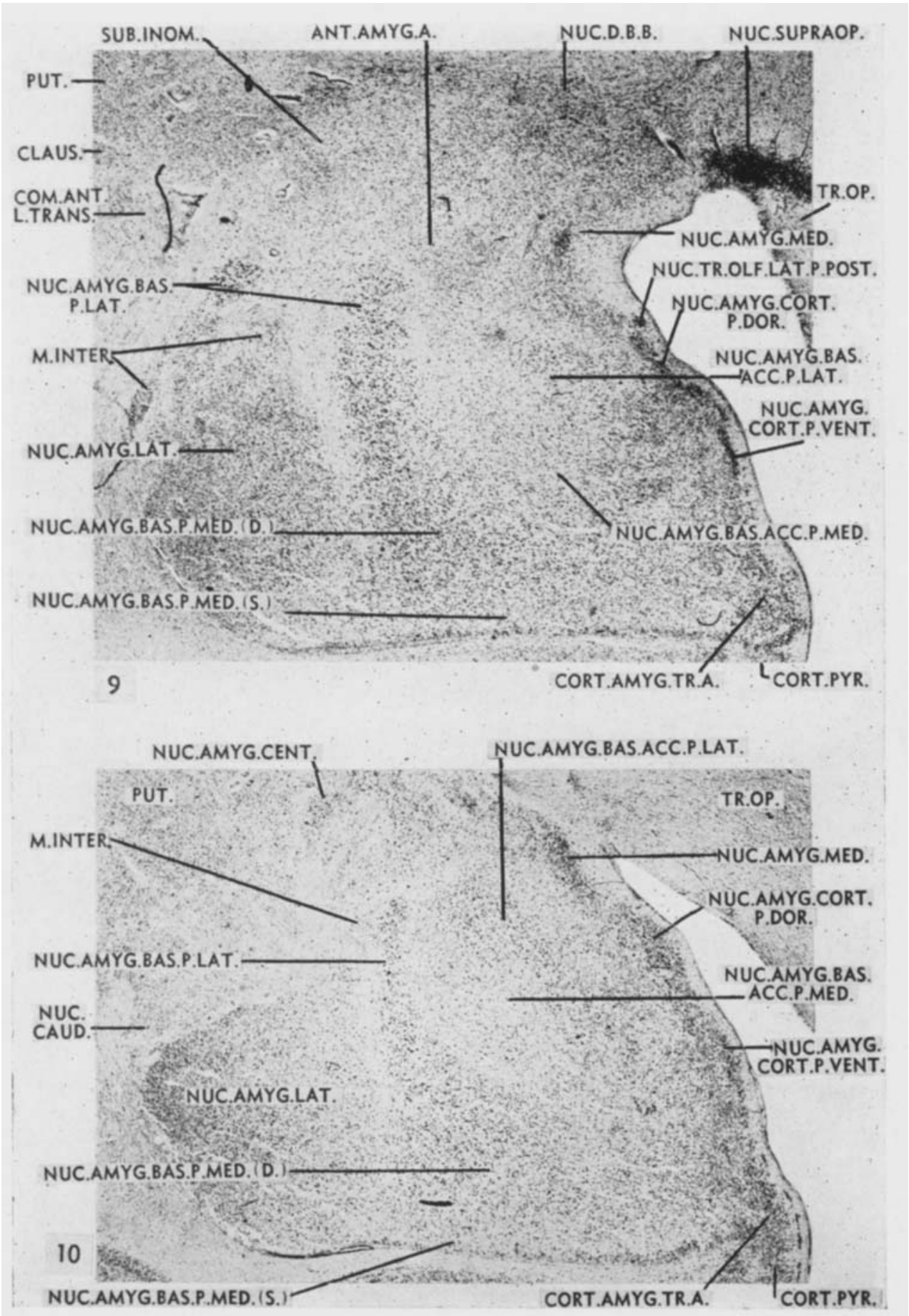



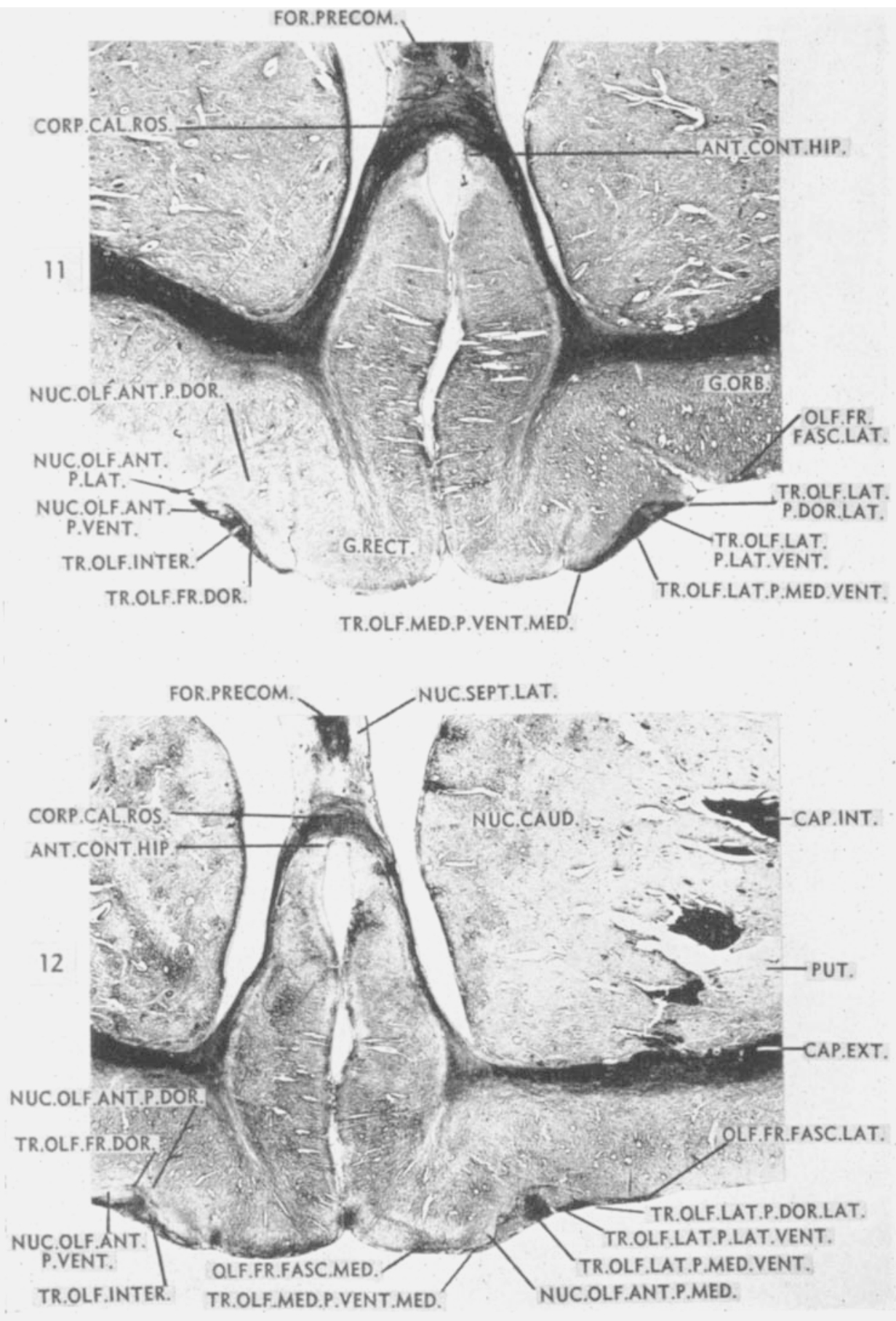

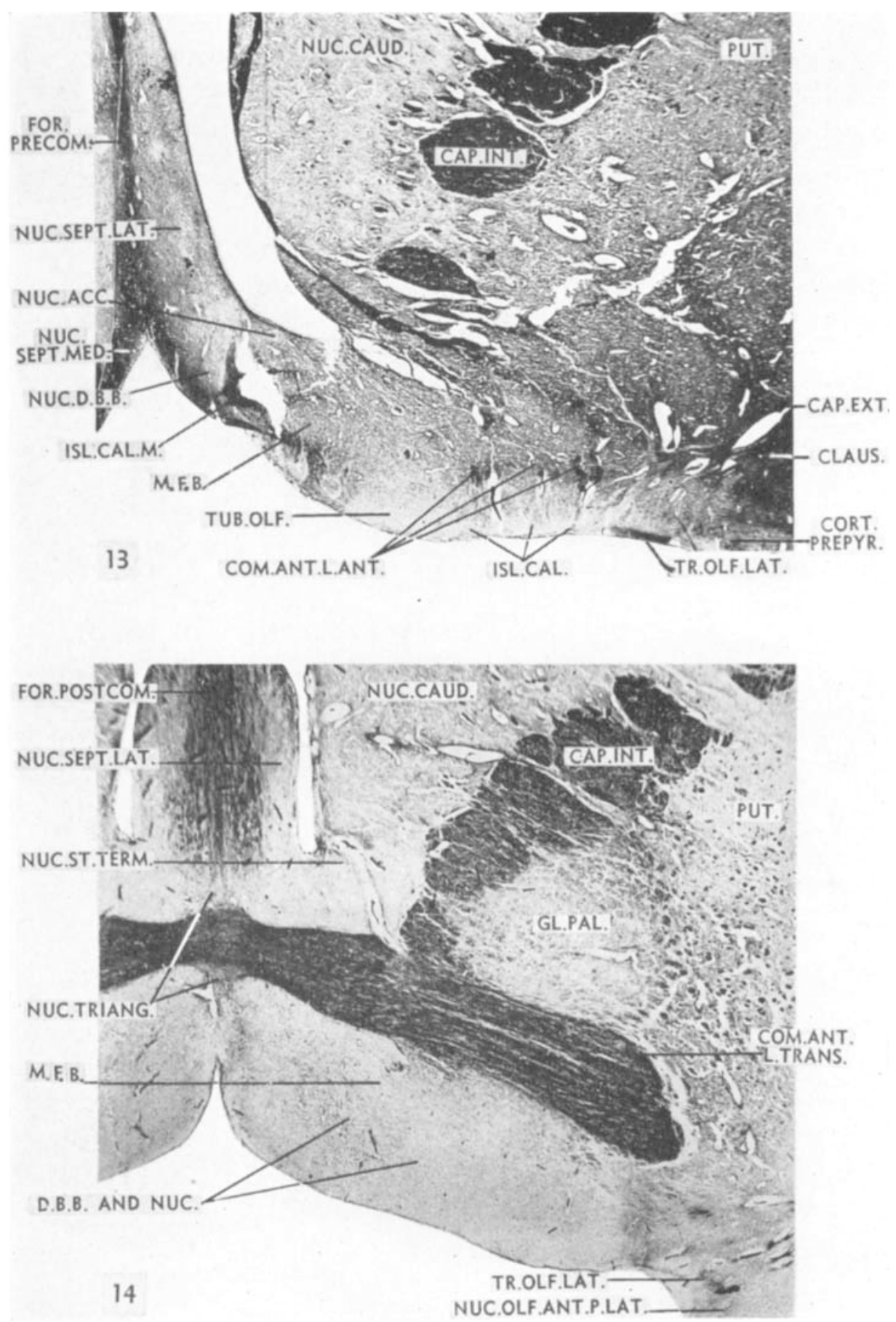


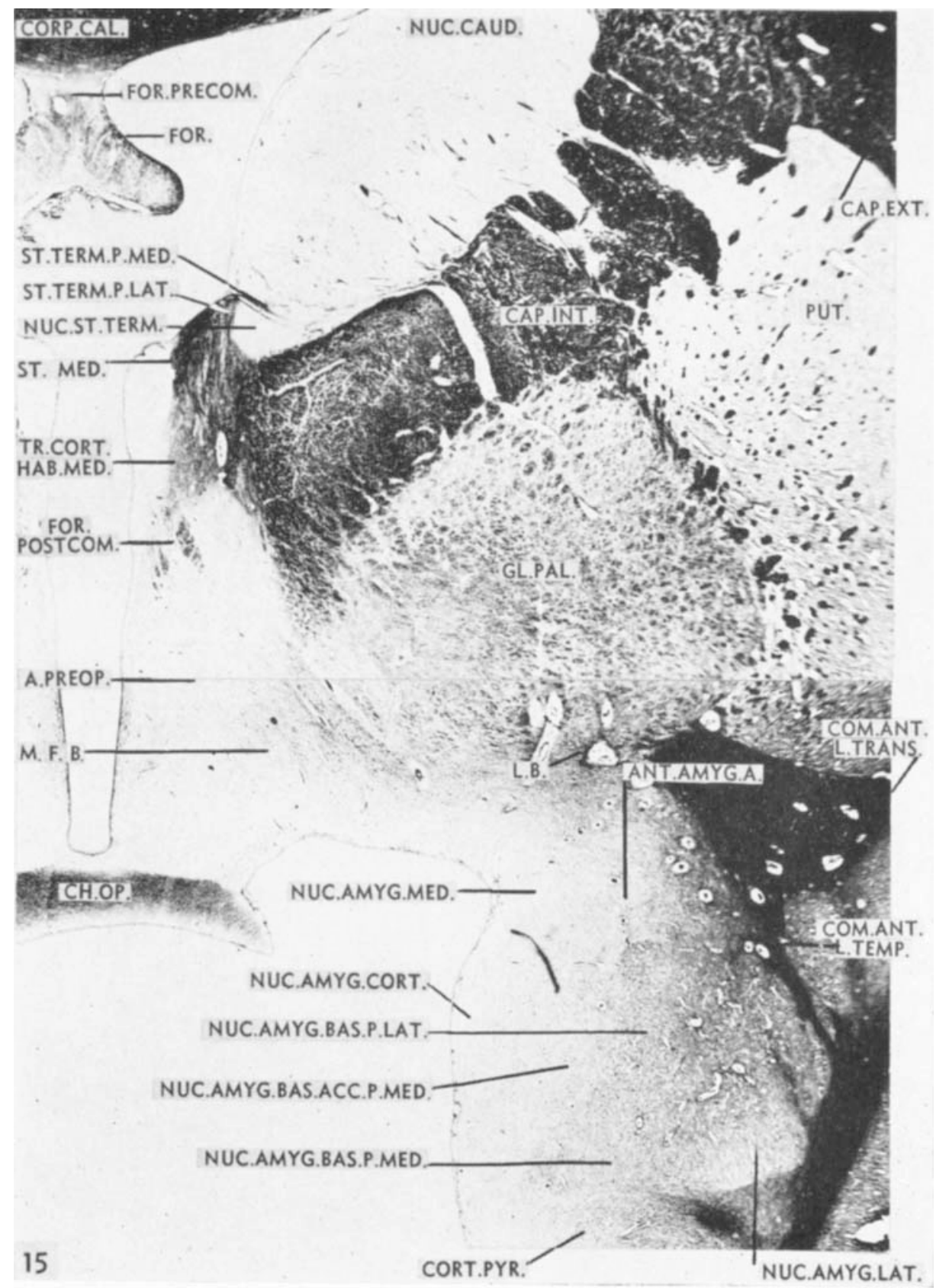


FDWARD W. LAUER
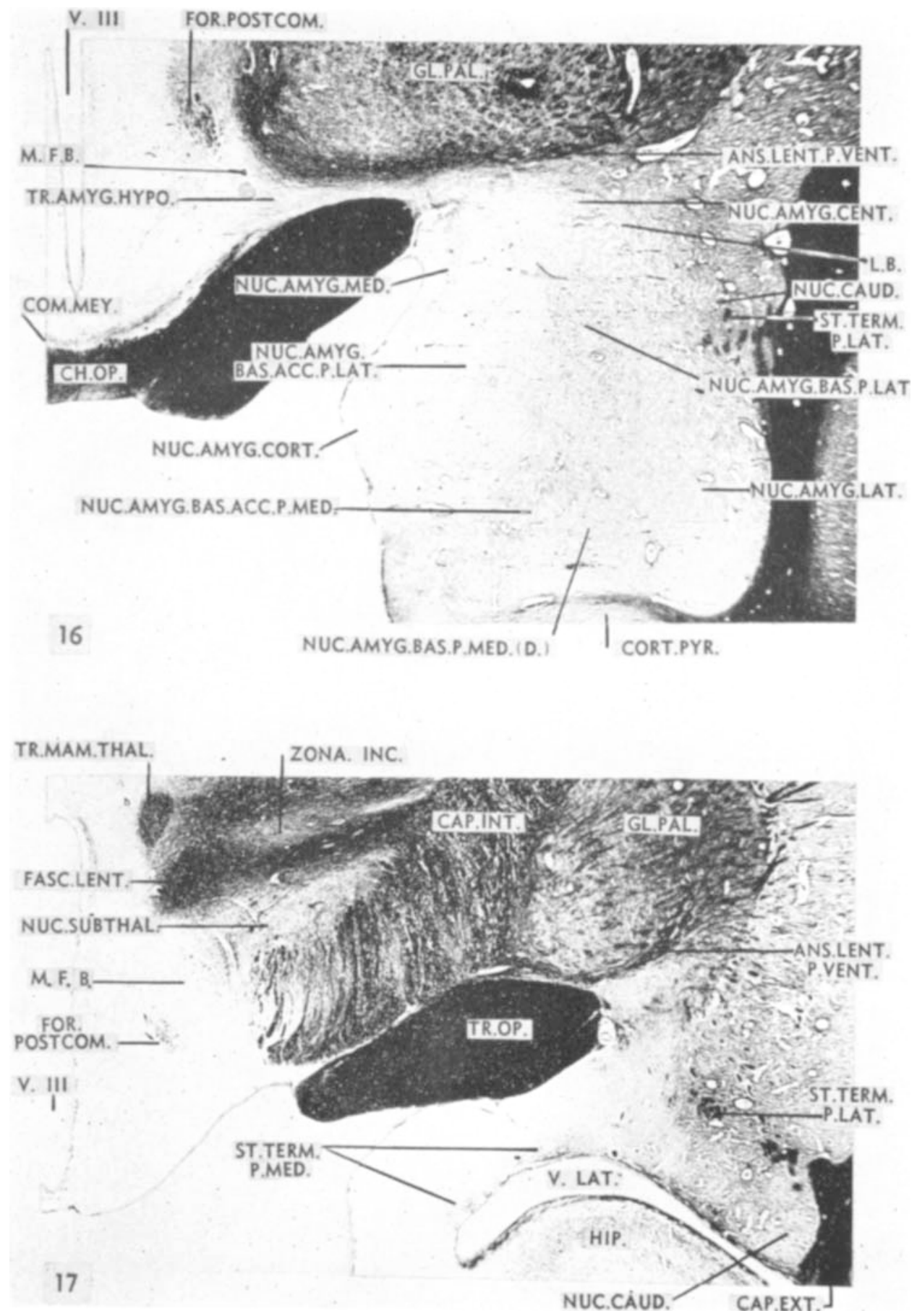